\title{
Gemfibrozil Protects Dopaminergic Neurons in a Mouse Model of Parkinson's Disease via PPAR $\alpha$-Dependent Astrocytic GDNF Pathway
}

\author{
Carl G. Gottschalk, ${ }^{1}$ Malabendu Jana, ${ }^{1,2}$ Avik Roy, ${ }^{1,2}{ }^{\circledR}$ Dhruv R. Patel, ${ }^{1}$ and ${ }^{\circledR}$ Kalipada Pahan ${ }^{1,2}$ \\ ${ }^{1}$ Department of Neurological Sciences, Rush University Medical Center, Chicago 60612, and ${ }^{2}$ Division of Research and Development, Jesse Brown \\ Veterans Affairs Medical Center, Chicago 60612
}

Parkinson's disease (PD) is the most common neurodegenerative movement disorder in humans. Despite intense investigations, effective therapies are not yet available to halt the progression of PD. Gemfibrozil, a Food and Drug Administrationapproved lipid-lowering drug, is known to decrease the risk of coronary heart disease by increasing the level of high-density lipoprotein cholesterol and decreasing the level of low-density lipoprotein cholesterol. This study underlines the importance of gemfibrozil in protecting dopaminergic neurons in an animal model of PD. Oral administration of the human equivalent dose of gemfibrozil protected tyrosine hydroxylase $(\mathrm{TH})$-positive dopaminergic neurons in the substantia nigra pars compacta and TH fibers in the striatum of 1-methyl-4-phenyl-1,2,3,6-tetrahydropyridine (MPTP)-insulted mice of both sexes. Accordingly, gemfibrozil also normalized striatal neurotransmitters and improved locomotor activities in MPTP-intoxicated mice. Gemfibrozil-mediated protection of the nigrostriatal and locomotor activities in WT but not PPAR $\alpha^{-1-}$ mice from MPTP intoxication suggests that gemfibrozil needs the involvement of peroxisome proliferator-activated receptor $\alpha$ (PPAR $\alpha)$ in protecting dopaminergic neurons. While investigating further mechanisms, we found that gemfibrozil stimulated the transcription of glial-derived neurotrophic factor (GDNF) gene in astrocytes via PPAR $\alpha$ and that gemfibrozil protected nigral neurons, normalized striatal fibers and neurotransmitters, and improved locomotor activities in MPTP-intoxicated Gfaf ${ }^{\text {cre }}$ mice, but not $G d n f^{\Delta \text { astro }}$ mice lacking GDNF in astrocytes. These findings highlight the importance of the PPAR $\alpha$-dependent astroglial GDNF pathway in gemfibrozil-mediated protection of dopaminergic neurons in an animal model of PD and suggest the possible therapeutic use of gemfibrozil in PD patients.

Key words: GDNF; gemfibrozil; PPAR $\alpha$

Significance Statement

Increasing the level of glial cell-derived neurotrophic factor (GDNF) in the brain is important for the protection of dopamine neurons in Parkinson's disease (PD). Although gene manipulation and GDNF protein infusion into the brain are available options, it seems from the therapeutic angle that the best option would be to stimulate/induce the production of GDNF in vivo in the brain of PD patients. Here, we delineate that gemfibrozil, a lipid-lowering drug, stimulates GDNF in astrocytes via peroxisome proliferator-activated receptor $\alpha(\operatorname{PPAR} \alpha)$. Moreover, gemfibrozil protected nigral neurons, normalized striatal fibers and neurotransmitters, and improved locomotor activities from MPTP toxicity via the PPAR $\alpha$-dependent astroglial GDNF pathway. These studies highlight a new property of gemfibrozil and suggest its possible therapeutic use in PD patients.

Received Dec. 19, 2019; revised Jan. 16, 2021; accepted Jan. 18, 2021.

Author contributions: C.G.G., M.J., and K.P. designed research; C.G.G., M.J., A.R., and D.R.P. performed research; C.G.G. analyzed data; K.P. wrote the paper.

This study was supported by Department of Veterans Affairs Merit Award 1101BX003033; National Institutes of Health Grants NS-083054 and NS-108025 to K.P; and Department of Veterans Affairs Research Career Scientist Award 11K6 BX004982 to K.P.

The authors declare no competing financial interests.

Correspondence should be addressed to Kalipada Pahan at Kalipada_Pahan@rush.edu.

https://doi.org/10.1523/JNEUROSCI.3018-19.2021

Copyright (c) 2021 the authors

\section{Introduction}

Parkinson's disease (PD) is second only to Alzheimer's disease $(\mathrm{AD})$ as the most common neurodegenerative disease. The pathologic hallmark of $\mathrm{PD}$ is the loss of dopaminergic neurons in the substantia nigra pars compacta (SNpc) and their projections to the striatum. The loss of these neurons and their projections result in inadequate concentrations of dopamine in the striatum (Kalia and Lang, 2015). The manifestation of the cardinal motor deficits (tremor, rigidity, akinesia, and bradykinesia) occur only after a $70 \%$ loss of dopaminergic neurons occurs in the SNpc, and a 30\% reduction in striatal dopamine concentrations 
Table 1. Antibodies used in this study

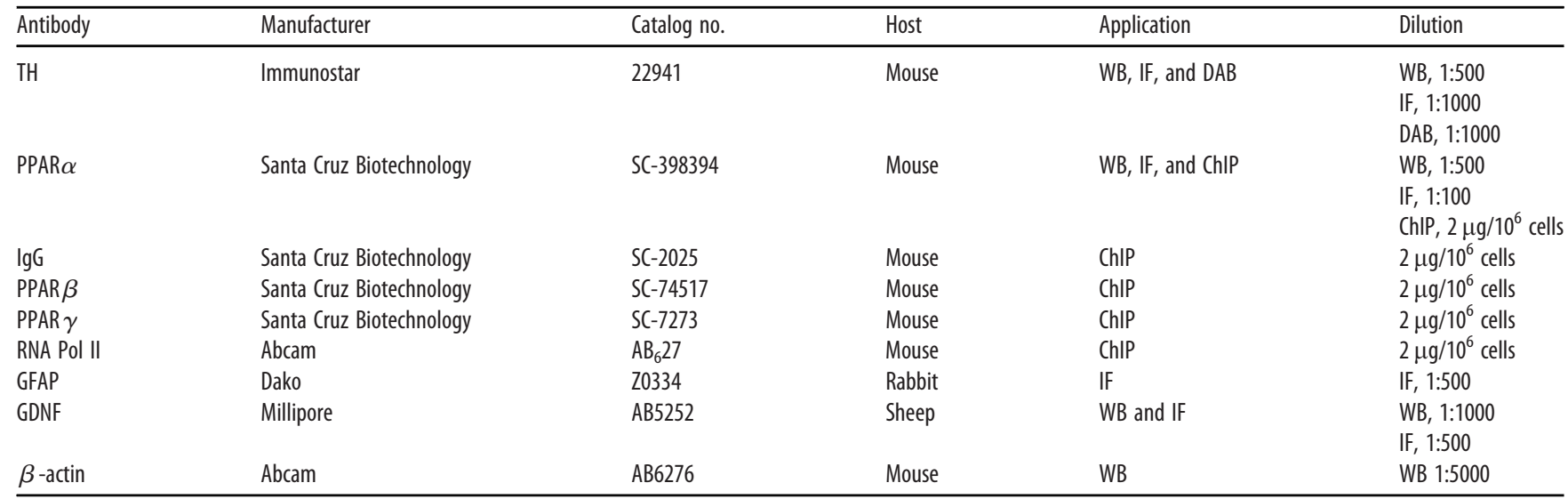

WB, Western blot; IF, immunofluorescence.

(Emamzadeh and Surguchov, 2018). Generally speaking, a polypharmacy approach is used to rescue striatal dopamine concentrations in an effort to reduce the motor deficits; however, many of these interventions have significant side effects (Emamzadeh and Surguchov, 2018). Levodopa, COMT (catechol-O-methyltransferase) inhibitors, dopamine agonists, and acetylcholinesterase inhibitors produce significant side effects because of their off-target effects in adjacent mesolimbic/frontal regions and via direct pharmacological interactions with one another (Diederich et al., 2009; Hindle, 2010). In addition, many of these therapies are themselves oxidative and, as such, potentiate the continued loss of dopaminergic neurons via their production of reactive oxygen and nitrogen species (Mhyre et al., 2012). Therefore, finding alternative approaches for the protection of dopaminergic neurons is an important area of research.

Gemfibrozil, known as Lopid in the pharmacy, has been used safely in humans for the treatment hypertriglyceridemia since its Food and Drug Administration (FDA) approval in 1982. We and others have demonstrated that in addition to lipid lowering, gemfibrozil is capable of modulating the expression of proinflammatory molecules (Pahan et al., 2002; Xu et al., 2005; Roy and Pahan, 2009) and anti-inflammatory molecules (Corbett et al., 2012; Ghosh and Pahan, 2012), switching T-helper cells (Dasgupta et al., 2007), altering cell-to-cell contact (Roy et al., 2007), stimulating the expression of myelin-specific genes (Jana et al., 2012), suppressing the disease process of experimental allergic encephalomyelitis (Lovett-Racke et al., 2004; Dasgupta et al., 2007), increasing lysosomal biogenesis and autophagy (Ghosh et al., 2015), and reducing plaque load in an animal model of AD (Chandra and Pahan, 2019). Here, we described that gemfibrozil protected the nigrostriatal pathology and attenuated the motor deficits in an MPTP mouse model of PD via peroxisome proliferator-activated receptor $\alpha(\operatorname{PPAR} \alpha)$. While exploring the mechanism further, we found that gemfibrozil increased the transcription of glial cell line-derived neurotrophic factor (GDNF) gene in astrocytes via $\operatorname{PPAR} \alpha$ and protected the nigrostriatum in MPTP-intoxicated mice via astroglial GDNF. These results highlight a new property of gemfibrozil and suggest that this drug may be considered for therapeutic use in PD.

\section{Materials and Methods}

Reagents and antibodies. Cell culture media (DMEMF/12 containing antibiotic/antimycotic) and fetal bovine serum (FBS) were purchased from Thermo Fisher Scientific. Gemfibrozil was purchased from SigmaAldrich. Molecular-grade chemicals were obtained from either Sigma-
Table 2. PCR primers used in this study

\begin{tabular}{|c|c|c|}
\hline Gene & Forward $\left(5^{\prime}\right.$ to $\left.3^{\prime}\right)$ & Reverse ( $3^{\prime}$ to $\left.5^{\prime}\right)$ \\
\hline GDNF & CGCTGACCAGTGACTCCAAT & AAACGCACCCCCGATTTTTG \\
\hline GAPDH & GCACAGTCAAGGCCGAGAAT & GCCTTCTCCATGGTGGTGAA \\
\hline$G^{D N F^{\Delta a s t r o}}$ & CTGGATAGGAGTGAGAACAGC & ATGAATCCTTGAGTGACAGG \\
\hline GFAPcre (transgene) & GCGGTCTGGCAGTAAAAACTATC & GTGAAACAGCATTGCTGTCACTT \\
\hline GFAP ${ }^{c r e}$ (internal control) & TAGGCCACAGAATTGAAAGATCT & GTAGGTGGAAATTCTAGCATCATCC \\
\hline GDNF Proximal ChIP 1 & GCAGAGTCAACCTCGGAGTAA & CGTTGGCCAGACCAGTTCC \\
\hline GDNF proximal ChIP 2 & GCAGAGTCAACCTCGGAGT & TTTCTACCCTGAAGCGTTGG \\
\hline
\end{tabular}

Aldrich or BIO-RAD. Infrared dye-labeled secondary antibodies used for immunoblotting were purchased from Li-Cor Biosciences. Alexa Fluor secondary antibodies used for immunofluorescent staining were purchased from Jackson ImmunoResearch. Secondary antibodies for immunohistochemistry studies were purchased from Vector Laboratories, and dilutions were made according to the manufacturer instructions. Table 1 lists the antibodies used in this study, and Table 2 lists the primers used in this study.

Animals. Animal maintenance and experiments were carried out in accordance with National Institutes of Health guidelines and were approved by the Institutional Animal Care and Use Committee of the Rush University Medical Center (Chicago, IL). C57BL/6 (JAX stock \# 000664) wild-type (WT) mice were crossed with PPAR $\alpha$ knock-out mice $\left(\mathrm{PPAR} \alpha^{-I-}\right)$ to create homozygous knock-out breeding pairs. Gdnf floxed mice [B6.129S1 (Cg)-Gdnftm1.1Neas/J; stock \#014097, The Jackson Laboratory] were bred with transgenic mice expressing the Cre enzyme under the control of the Gfap promoter [B6.Cg-Tg (Gfap-cre) $73.12 \mathrm{Mvs} / \mathrm{J}$; stock \#012886, The Jackson Laboratory] to generate knockout mice with Gdnf deletion in the astroglial cells (Gdnf ${ }^{\Delta \text { astro }}$ mice). The final breeding step was performed using a homozygous breeding pair from F4 generation. All mice analyzed in this study were on a congenic C57BL/6J genetic background. Genotyping of the Gdnf floxed locus and $\mathrm{Gfap}^{\text {cre }}$ transgene was performed using PCR on DNA obtained from tail biopsy samples and detected by primers listed in Table 2. Mice were maintained on a 14/10 h light/dark cycle and given a continuous supply of food and water.

MPTP intoxication. The acute MPTP intoxication model was used to lesion the nigrostriatal pathway and to induce $\mathrm{PD}$-associated phenotypes (Ghosh et al., 2007, 2009; Jackson-Lewis and Przedborski, 2007). Briefly, mice of either sex were injected intraperitoneally with MPTP $(20 \mathrm{mg} / \mathrm{kg}$; Sigma-Aldrich) four times at $2 \mathrm{~h}$ intervals.

Gemfibrozil treatment. Gemfibrozil was solubilized in $0.5 \%$ methyl cellulose, and mice were treated with gemfibrozil once daily at a dose of $7.5 \mathrm{mg} / \mathrm{kg}$ in a volume of $50 \mu \mathrm{l}$ via gavage starting from $4 \mathrm{~h}$ after the last injection of MPTP. We adopted the time frame to avoid any effect of gemfibrozil on the metabolism of MPTP in the brain.

Typically, any animal experiment is justified with a $99 \%$ confidence interval that generates $p=0.99$ and $(1-p)=(1-0.99)=0.01 ; \varepsilon$ is the 
margin of error $=0.05$. Based on these values, the resultant sample size is as follows:

$N=\frac{1,28^{2} * 0.99(1-0.99)}{0.05^{2}}=\frac{1,28^{2} * 0.99 * 0.01}{0.05^{2}}=\frac{0.016}{0.0025}=6.48 \sim 6$.

Therefore, six mice ( $n=6)$ were used in each group.

Animal killing and tissue preparation. Following behavioral analysis, animals were anesthetized with injectable ketamine/xylazine and perfused with PBS for $5 \mathrm{~min}$. After perfusion, each brain was hemisected. One hemisphere was placed immediately into $4 \%$ paraformaldehyde and stored at $4^{\circ} \mathrm{C}$ until sectioning. Nigra and striatum were dissected out of the other hemisphere and stored at $-80^{\circ} \mathrm{C}$ until used for immunoblotting and HPLC applications.

Brain sectioning. Hemisected brains were removed from $4 \%$ paraformaldehyde and placed in $30 \%$ sucrose at $4^{\circ} \mathrm{C}$ for $24 \mathrm{~h}$. After a brief wash with PBS, the brains were mounted frozen on microtome stages, covered with crushed dry ice, and serially sectioned on a sliding microtome $(30 \mu \mathrm{m})$ into 24 -well plates containing cryoprotectant solution. Brain sections were stored at $-20^{\circ} \mathrm{C}$ before either immunofluorescence or diaminobenzidine (DAB) staining.

Isolation of primary mouse astrocytes. Astrocytes were isolated from mixed glial cultures of 2- to 3-d-old mouse pups according to the procedure described earlier (Khasnavis et al., 2014; Khasnavis and Pahan, 2014). Briefly, brains from pups $(n>10)$ were isolated and placed together in the DMEM/Nutrient Mixture F-12 (DMEM/F12) supplemented with $10 \%$ heat-inactivated fetal bovine serum. Astroglial cells were dissociated by trituration, and the single-cell suspension was equally plated in four to five poly-D-lysine-precoated T-75 flasks containing complete DMEM/F12 media. On day 9, the T-75 flasks containing mixed glial cultures were washed three times with DMEM/F-12 and subjected to shaking at $240 \mathrm{rpm}$ for $2 \mathrm{~h}$ at $37^{\circ} \mathrm{C}$ on a rotary shaker to remove microglia. After $2 \mathrm{~d}$, the shaking was repeated for $24 \mathrm{~h}$ to remove oligodendroglia and to ensure the complete removal of all nonastroglial cells. The attached cells were seeded onto new plates for further studies.

Real-time PCR. It was performed in the QuantStudio 3 sequence detection system (Applied Biosystems) per the manufacturer instructions. Total RNA was isolated from the primary astrocytes using the Quick-RNA MiniPrep Kit (catalog \#R1054 and \#R1055, ZYMO RESEARCH) following the manufacturer protocol. To remove any contaminating genomic DNA, total RNA was digested with DNase. One microgram of total RNA was reverse transcribed using oligo (dT) 12-18 as primer and M-MLV Reverse Transcriptase (catalog \#28025013, Thermo Fisher Scientific) in a $20 \mu \mathrm{l}$ reaction mixture. The resulting cDNA was appropriately diluted and then amplified using SYBR-Green Mastermix (catalog \#4472903, Thermo Fisher Scientific) and the primers listed in Table 2. Specificity was checked from the product size obtained by reverse transcriptase-coupled PCR using the primers (Table 2). GAPDH (glyceraldehyde-3-phosphate dehydrogenase) was used as the house-keeping gene. Data were processed by the Quant Studio 3 Design and Analysis Software version 1.5.1 software. The linearity of real-time PCR was monitored by the correlation coefficient $\left(R^{2}\right)$ of the curve that was $\geq 0.98$.

Clustered regularly interspaced short palindromic repeat editing of GDNF gene in astrocytes. Mouse primary astrocytes were plated in 6well plates at a density of $1.8 \times 10^{6}$ cells/well with DMEM/F-12 containing FBS (10\%) and an antibiotic-antimycotic mixture at $37^{\circ} \mathrm{C}$ with $5 \%$ $\mathrm{CO}_{2}$. After $24 \mathrm{~h}$, cells were infected with GFP-control lentivirus and GDNF single guide RNA (sgRNA) CRISPR (clustered regularly interspaced short palindromic repeat) all-in-one lentivirus (mouse) (viral titer $=6 \times 10^{6} \mathrm{IU} / \mathrm{ml}$ ) according to the protocol provided by the manufacturer (Applied Biological Materials). Following the infection, cells were incubated at $37^{\circ} \mathrm{C}$ with $5 \% \mathrm{CO}_{2}$. After overnight incubation, culture medium was replaced with $2 \mathrm{ml}$ of complete medium, and cells were incubated for $48 \mathrm{~h}$ followed by monitoring genomic editing by Western blot.

Immunoblotting and densitometric analyses. For whole-cell and tissue lysates, samples were homogenized in RIPA buffer containing protease and phosphatase inhibitors (Sigma-Aldrich), rotated end over end for $30 \mathrm{~min}$ at $4^{\circ} \mathrm{C}$ and centrifuged for $10 \mathrm{~min}$ at $15,000 \times g$. The supernatant was aliquoted and stored at $-80^{\circ} \mathrm{C}$ until use. Protein concentrations were determined using the BCA Protein Assay (Thermo Fisher Scientific), and a 15-30 $\mu$ g sample was heat denatured and resolved on $12 \%$ or $15 \%$ polyacrylamide-SDS gels in MES buffer ( $50 \mathrm{~mm}$ MES, 50 mм Tris base, $0.1 \%$ SDS, 1 mм EDTA, pH 7.3) or $1 \times$ SDS Running Buffer. Proteins were transferred to $0.45 \mu \mathrm{m}$ nitrocellulose membranes in Towbin Buffer [25 mm Tris, $192 \mathrm{~mm}$ glycine, 20\% (w/v) methanol] under wet conditions (40 V for $120 \mathrm{~min}$ ). Membranes were blocked for $1 \mathrm{~h}$ with blocking buffer (Li-Cor), incubated with primary antibodies (Table 1) overnight at $4^{\circ} \mathrm{C}$ under shaking conditions, washed, incubated with IRDye-labeled secondary antibodies (1:5000; Li-Cor) for $45 \mathrm{~min}$ at room temperature, washed, and visualized with the Odyssey Infrared Imaging System (Li-Cor). Blots were converted to binary, analyzed using Image J and normalized to the loading control ( $\beta$-actin).

HPLC. Striatal levels of dopamine, dihydroxyphenylacetic acid (DOPAC), and homovanillic acid (HVA) were quantified by HPLC as described previously (Roy et al., 2013; Chandra et al., 2017). Following the dissection of a $1 \mathrm{~mm}^{3}$ portion of the striatum, the samples frozen on dry ice and tissue was stored at $-80^{\circ} \mathrm{C}$ for processing the next day. Tissues were sonicated in $0.2 \mathrm{M}$ perchloric acid containing isoproterenol and then spun at $20,000 \times g$ for $30 \mathrm{~min}$. After that, $10 \mu \mathrm{l}$ of the supernatant was injected onto an Eicompak SC-3ODS column (complete stand-alone HPLC-electrochemical detection system; catalog \#EiCOMHTEC-500, JM SCIENCE INC) and analyzed following the manufacturer protocol.

Immunofluorescence staining. We performed immunofluorescence staining using a procedure described previously (Patel et al., 2018). Briefly, primary mouse astrocytes were washed three times with $1 \times \mathrm{PBS}$, fixed in $4 \%$ paraformaldehyde for $10 \mathrm{~min}$ or with chilled methanol overnight, washed again with $1 \times$ PBS, and incubated first with monoclonal or polyclonal primary antibodies listed in Table 1 and then with the Cy2- or Cy5-conjugated secondary antibodies. Following secondary antibody incubation, coverslips were rinsed in $1 \times$ PBS, mounted on slides in Fluormount (Sigma-Aldrich), and imaged using an Olympus BX41 Fluorescence Microscope equipped with a Hamamatsu ORCA03G Camera.

Immunohistochemistry using DAB staining. Serial sections of brain tissue were removed from one column per 24-well plate, washed six times $(10 \mathrm{~min} / \mathrm{wash})$ in filtered PBS containing 5\% Tween (PBSt). To block endogenous peroxide activity, sections were incubated in a solution of $3 \%$ hydrogen peroxide $\left(\mathrm{H}_{2} \mathrm{O}_{2}\right)$ and $10 \%$ methanol for $5 \mathrm{~min}$. After, the sections were blocked in $2 \%$ bovine serum albumin for $1 \mathrm{~h}$. Sections were then incubated with primary anti-mouse tyrosine hydroxylase (TH; Immunostar) antibody at a 1:500 dilution overnight at $4^{\circ} \mathrm{C}$ under shaking conditions. The following day, the sections were washed three times for $10 \mathrm{~min}$ each and blocked in 1:10 dilution of normal horse serum for $1 \mathrm{~h}$ at room temperature. After blocking, the sections were incubated in biotinylated anti-mouse IgG secondary antibody (BA-2000, Vector Laboratories) at a 1:100 dilution in PBSt and 2\% normal horse serum for $4 \mathrm{~h}$ at room temperature. Sections were washed briefly with PBSt and then incubated for $1 \mathrm{~h}$ at $30^{\circ} \mathrm{C}$ with the Vectastain Elite $\mathrm{ABC}$ Peroxidase Kit (Vector Laboratories). To develop color, the sections were transferred into a 6-well tissue-staining apparatus containing $20 \mathrm{mg}$ of DAB $(\sigma)$ solubilized in $40 \mathrm{ml}$ of PBSt and $20 \mu \mathrm{l}$ of $30 \% \mathrm{H}_{2} \mathrm{O}_{2}$ for $5 \mathrm{~min}$. The sections were then mounted on glass slides and left to dry overnight. The following day, the slides were exposed to an alcohol gradient and two brief washes with xylene before coverslipping using Cryoseal 60 (Richard Allen Scientific). Serial nigral and striatal sections were viewed on a bright-light microscope (BX61 microscope, Olympus; attached to a DXM1200 digital camera, Nikon). Unbiased stereology from serially sectioned nigral sections was used to quantify $\mathrm{TH}$ cell expression in the SNPc as described previously (Mondal et al., 2019). Optical density reflecting dopaminergic fiber innervation in the striatum was completed using ImageJ, as described previously (Ghosh et al., 2009; Prorok et al., 2019).

Immunohistochemistry using fluorescence microscopy. Free-floating brain sections were immunostained as described previously (Ghosh 
A

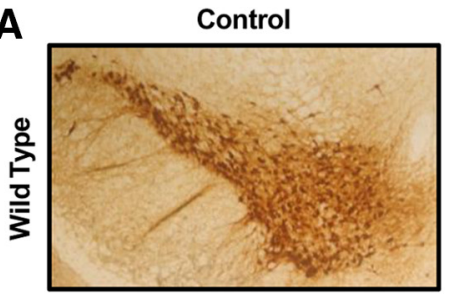

B

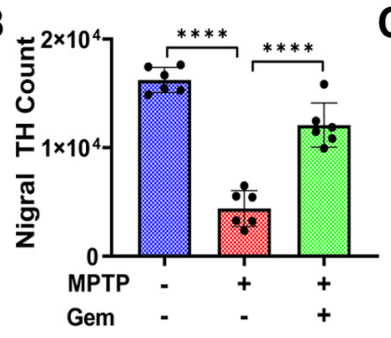

C

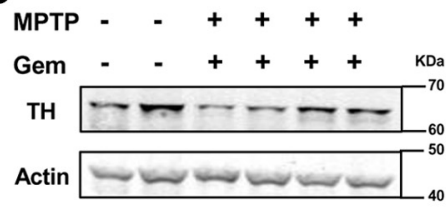

E
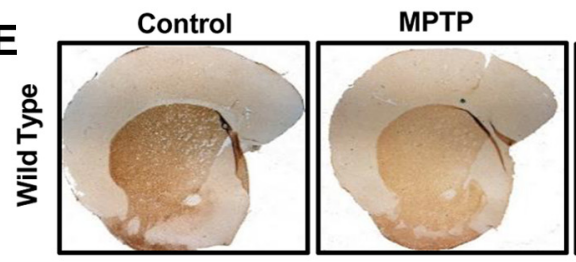

\section{G}

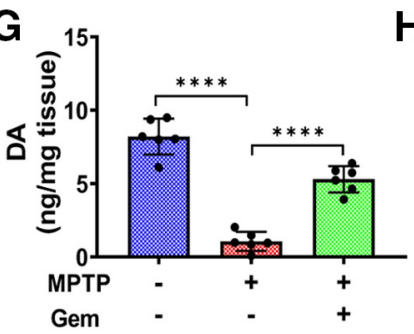

H
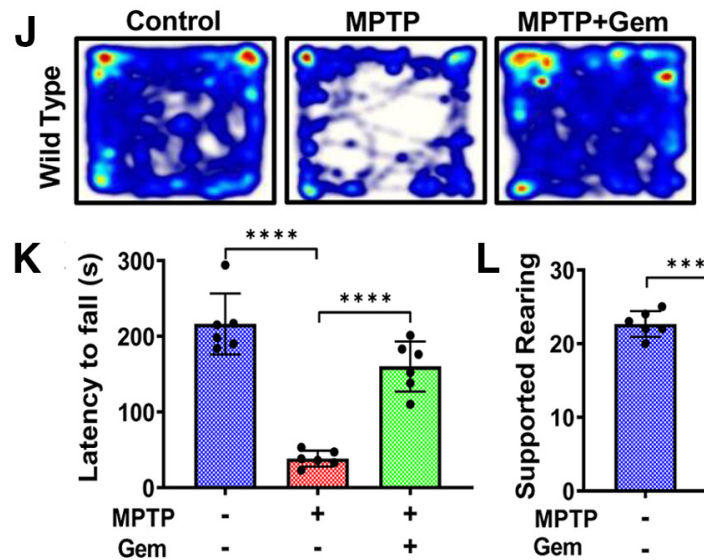

MPTP+Gem

MPTP

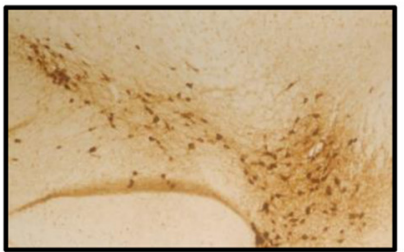

\section{D}
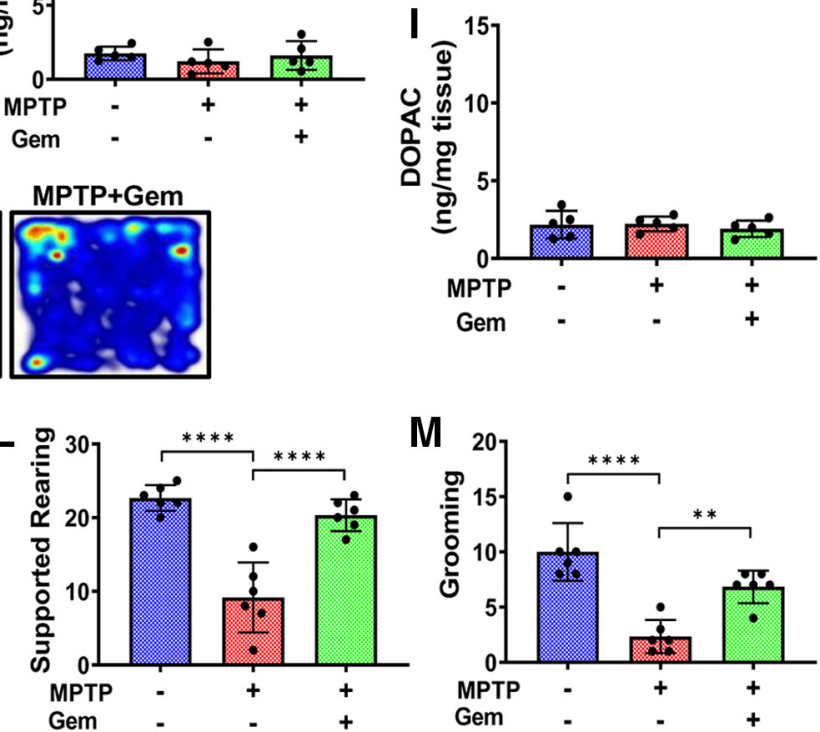
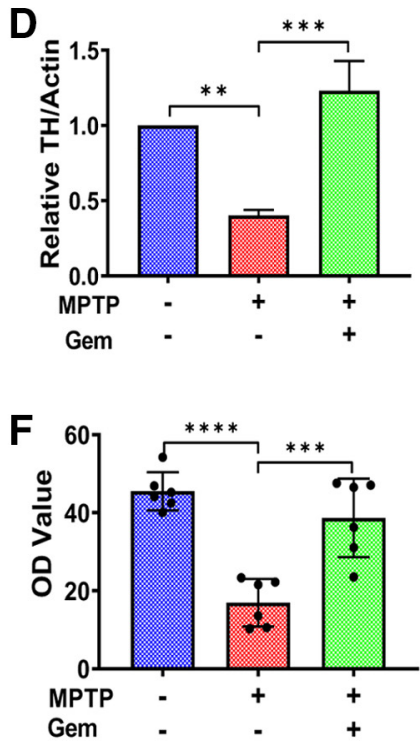

M

MPTP+Gem

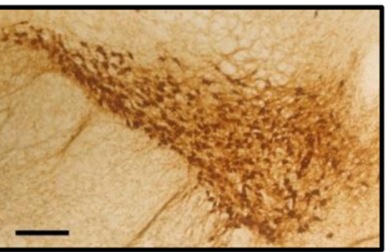

Gem - $\quad$ - $\quad+$

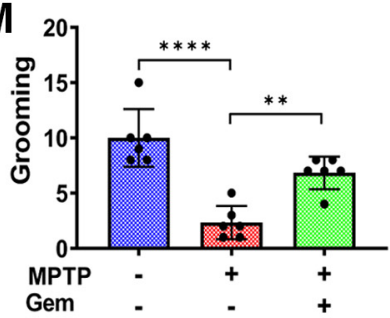

Figure 1. Gemfibrozil rescues nigrostriatal pathology in MPTP mouse model of PD. The 6 - to 8 -week-old C57BL/6 mice $(n=6$ per group) were lesioned with MPTP (20 mg/kg body weight/ injection, four intraperitoneal injections at $2 \mathrm{~h}$ intervals). At $4 \mathrm{~h}$ following the last MPTP injection, mice were fed gemfibrozil $(7.5 \mathrm{mg} / \mathrm{kg}$ body weight/d) via oral gavage for $7 \mathrm{~d}$. $A, B$, Before being killed on day 7 , all of the animals were subjected to behavioral assay. $\boldsymbol{A}, \boldsymbol{B}$, Representative TH immunostaining $(\boldsymbol{A})$, and stereological counting $(\boldsymbol{B})$ of nigral TH neurons. Results are the mean \pm SEM of six animals per group with the significance of the mean tested by one-way ANOVA $\left(F_{(2,15)}=78.69>\right.$ F-critical $\left.\left.\left(F_{c}\right)=3.68\right) * * * * p<0.0001\right)$. A post hoc Sidak's pairwise test results in $* * * * p<0.0001$ for control versus MPTP, and $* * * * p<0.0001$ for MPTP versus MPTP + gemfibrozil (Gem). C, D, TH protein concentration in the nigra was visualized via immunoblot $(\boldsymbol{C})$ and quantified using densitometry $(\boldsymbol{D})$. Results are the mean \pm the SEM of three independent immunoblots with significance of the mean tested by one-way ANOVA $\left(F_{(2,6)}=\right.$ $\left.40.71>F_{\mathrm{c}}=5.14 ; * * * p=0.0003\right)$, followed by a post hoc Sidak's test, resulting in $* * p=0.0015$ for control versus MPTP, and $* * * p=0.0002$ for MPTP versus MPTP + Gem. $E$, $\boldsymbol{F}$, Representative immunostaining to visualize TH fiber in the striatum $(\boldsymbol{E})$ and corresponding optical density analyses $(\boldsymbol{F})$. Results are the mean \pm the SEM of six level-matched striatal sections per animal. Significance of the mean was tested by a one-way ANOVA $\left(\mathrm{F}_{(2,15)}=24.76>F_{\mathrm{c}}=3.68 ; * * * * p<0.0001\right)$, followed by a post hoc Sidak's test between the groups resulting in $* * * * p<0.0001$ for control versus MPTP, and $* * * p=0.0002$ for MPTP versus MPTP + Gem. $\mathbf{G}-\boldsymbol{I}$, Analysis of DA (G), HVA $(\boldsymbol{H})$, and DOPAC (I) in striatum. Results are the mean \pm SEM of six animals per group with significance of the mean tested by ANOVA that results, for striatal dopamine (DA) concentrations in $F_{(2,15)}=84.87>F_{\mathrm{c}}=3.89$ (****p<0.0001). A post hoc Sidak's test results in $* * * * p<0.0001$ for control versus MPTP, and $* * * * p<0.0001$ for MPTP versus MPTP + Gem. No significant differences were observed in HVA or DOPAC levels among the groups. $\boldsymbol{J}$, Representative heat map from the open field analysis. $\boldsymbol{K}$, Rotarod analysis measuring latency to fall. Results are the mean \pm SEM of six animals per group, with the significance of the mean tested by one-way ANOVA $\left(F_{(2,15)}=52.52>F_{c}=3.89 ; * * * * p<0.0001\right)$, followed by a Sidak's test resulting in $* * * * p<0.0001$ for control versus MPTP, and $* * * * p<0.0001$ for MPTP versus MPTP + Gem. $L$, Supported rearing counts; one-way ANOVA $\left(F_{(2,15)}=30.93>F_{\mathrm{c}}=3.89 ; * * * * p<0.0001\right)$, post hoc Sidak's test resulting in 

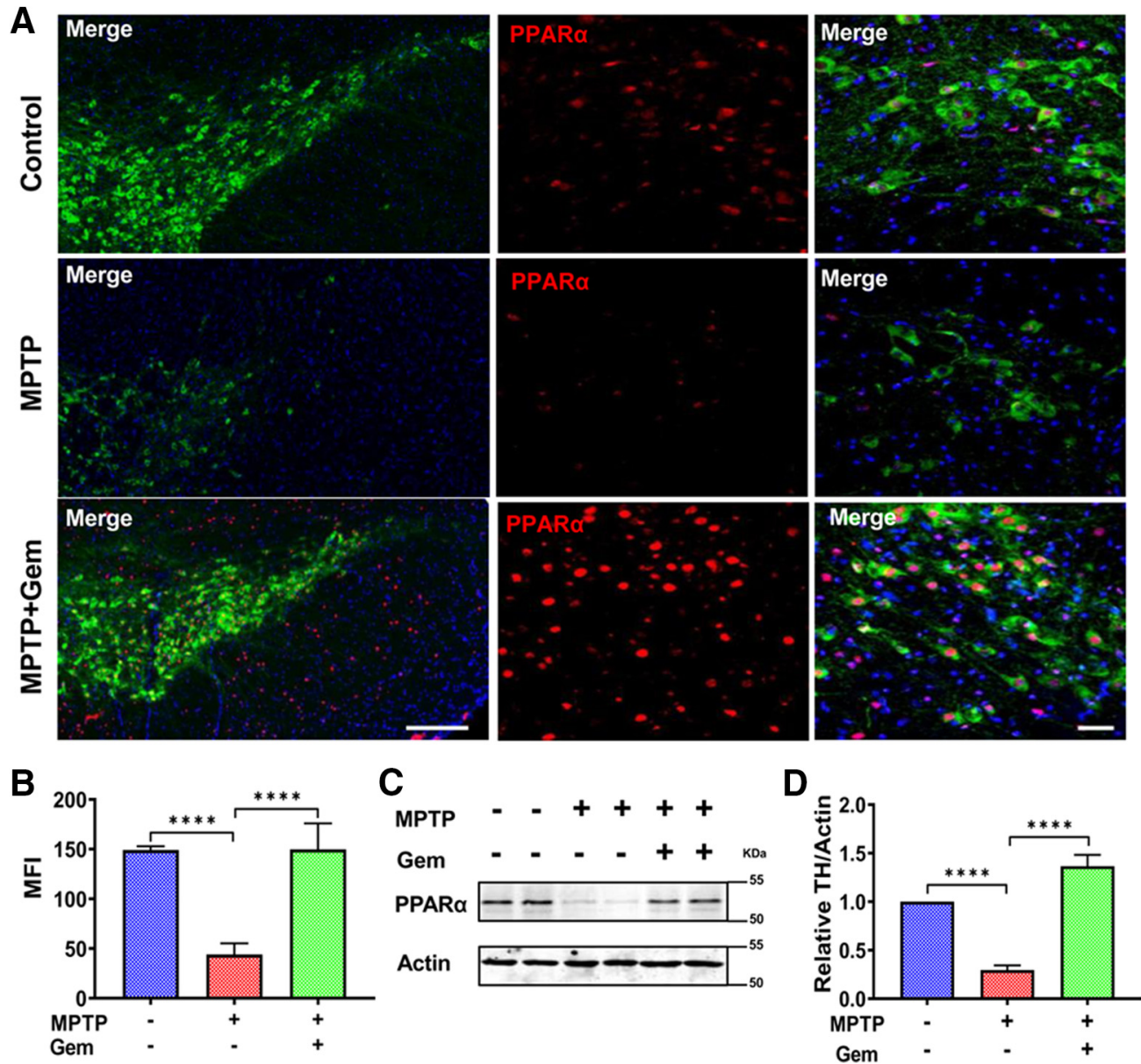

Figure 2. Gemfibrozil treatment upregulates PPAR $\alpha$ expression in the MPTP mouse model of MPTP. The 6- to 8-week-old C57BL/6 ( $n=6 /$ group) were lesioned with MPTP (20 mg/kg body weight/injection, four intraperitoneal injections at every $2 \mathrm{~h}$ interval). At $4 \mathrm{~h}$ following the last MPTP injection, mice were fed gemfibrozil (7.5 mg/kg body weight/d) via oral gavage for $7 \mathrm{~d}$. $A$, Representative immunofluorescence staining for TH (cy-3) and PPAR $\alpha$ (cy-5). DAPI was used to visualize the nucleus. Scale bar, $20 \mu \mathrm{m}$. $\boldsymbol{B}, \mathrm{MFI}$ of PPAR $\alpha$. Results are the mean \pm the SEM of six fields per animal, containing $>20$ cells within the field. Significance of the mean tested by one-way ANOVA $\left(F_{(2,15)}=81.46>F_{\mathrm{c}}=3.89 ; * * * * p<0.0001\right)$, followed by a post hoc Sidak's pairwise comparison test resulting in $* * * * p<0.0001$ for control versus MPTP and $* * * * p<0.0001$ for MPTP versus MPTP $+G e m$. C, $\boldsymbol{D}$, Nigral lysates were immunoblotted for $\operatorname{PPAR} \alpha(\boldsymbol{C})$ and quantified via densitometric analysis $(\boldsymbol{D})$. Results are the mean \pm the SEM of three independent immunoblots with significance of the mean tested by ANOVA $\left(F_{(2,6)}=\right.$ $\left.168.8>F_{\mathrm{c}}=3.89 ; * * * * p<0.0001\right)$ followed by a post hoc Sidak's test to determine significant differences among the groups, resulting in $* * * * p<0.0001$ for control versus MPTP, and $* * * * p<0.0001$ for MPTP versus MPTP + Gem.

et al., 2007, 2009). Briefly, samples were incubated in PBS containing $0.05 \%$ Tween 20 (PBST) and $10 \%$ sucrose for $3 \mathrm{~h}$ and then $30 \%$ sucrose overnight at $4^{\circ} \mathrm{C}$. Brain was then embedded in O.C.T. Compound (Tissue Tech) at $-80^{\circ} \mathrm{C}$ and processed for conventional cryosectioning. Forty micrometer free-floating sections were treated with cold ethanol $\left(-20^{\circ} \mathrm{C}\right)$ followed by washing in PBS, blocking with $3 \%$ bovine serum albumin in PBST, and double labeling with antibodies (Table 1). After several PBST washes, sections were further incubated with Cy2 and Cy5 (Jackson ImmunoResearch) followed by mounting and analysis under the Olympus BX41 Fluorescence Microscope.

Chromatin immunoprecipitation assay. The mouse Gdnf promoter was analyzed for predicted transcription factor binding sites using MatInspector software with the matrix threshold set at 0.85 . The primer sets that can amplify fragments flanking the peroxisome proliferator response element (PPRE) in the mouse Gdnf promoter were then designed upstream and downstream of transcription factor binding sites

$\leftarrow$

$* * * * p<0.0001$ for control versus MPTP and $* * * * p<0.0001$ for MPTP versus MPTP + Gem. $M$, Grooming counts; one-way ANOVA $\left(F_{(2,15)}=23.78>F_{c}=3.89\right.$; $* * * * p<0.0001)$, post hoc Sidak's test resulting in $* * * * p<0.0001$ for control versus MPTP and $* * p=0.0022$ for MPTP versus MPTP + Gem. to amplify immunoprecipitated DNA. Chromatin was prepared and immunoprecipitated as described previously (Roy et al., 2013; Corbett et al., 2015). Briefly, gemfibrozil-treated $(10 \mu \mathrm{M})$ mouse primary astrocytes were fixed with formaldehyde (1.42 final volume) and quenched with $125 \mathrm{~mm}$ glycine. Astrocytes were then pelleted and lysed in IP buffer containing $150 \mathrm{~mm} \mathrm{NaCl} ; 50 \mathrm{~mm}$ Tris- $\mathrm{HCl}, \mathrm{pH}$ 8.0; $5 \mathrm{~mm}$ EDTA; Nonidet P-40 $(0.5 \% \mathrm{v} / \mathrm{v})$; and Triton X-100 $(1.0 \% \mathrm{v} / \mathrm{v})$. After a single wash with $500 \mu$ l of IP buffer, the pellet was resuspended in an equal volume of IP buffer and sonicated. Sheared chromatin was separated into two fractions (one for input). The remaining fraction was incubated overnight at $4^{\circ} \mathrm{C}$ under rotating conditions using the antibodies listed in Table 1, followed by incubation with protein G-agarose (Santa Cruz Biotechnology) for $2 \mathrm{~h}$ at $4^{\circ} \mathrm{C}$. Beads were then washed five times with cold IP buffer, and a total of $50 \mu \mathrm{l}$ of $10 \%$ Chelex $\left(10 \mathrm{~g} / 100 \mathrm{ml} \mathrm{H}_{2} \mathrm{O}\right)$ was added to the washed protein $\mathrm{G}$ beads and vortexed. The Chelex/protein $\mathrm{G}$ bead suspension was boiled for $10 \mathrm{~min}$ and then allowed to return to room temperature. Proteinase $\mathrm{K}(100 \mu \mathrm{g} / \mathrm{ml})$ was then added, and the beads were incubated for $30 \mathrm{~min}$ at $55^{\circ} \mathrm{C}$ while shaking, followed by another round of boiling for $10 \mathrm{~min}$. The suspension was centrifuged, and the supernatant was collected and used directly as a template in PCR using the chromatin immunoprecipitation (ChIP) primers listed in Table 2.

Generation of mouse GDNF promoter-driven luciferase construct. Mouse genomic DNA isolated from primary mouse astrocytes were used 

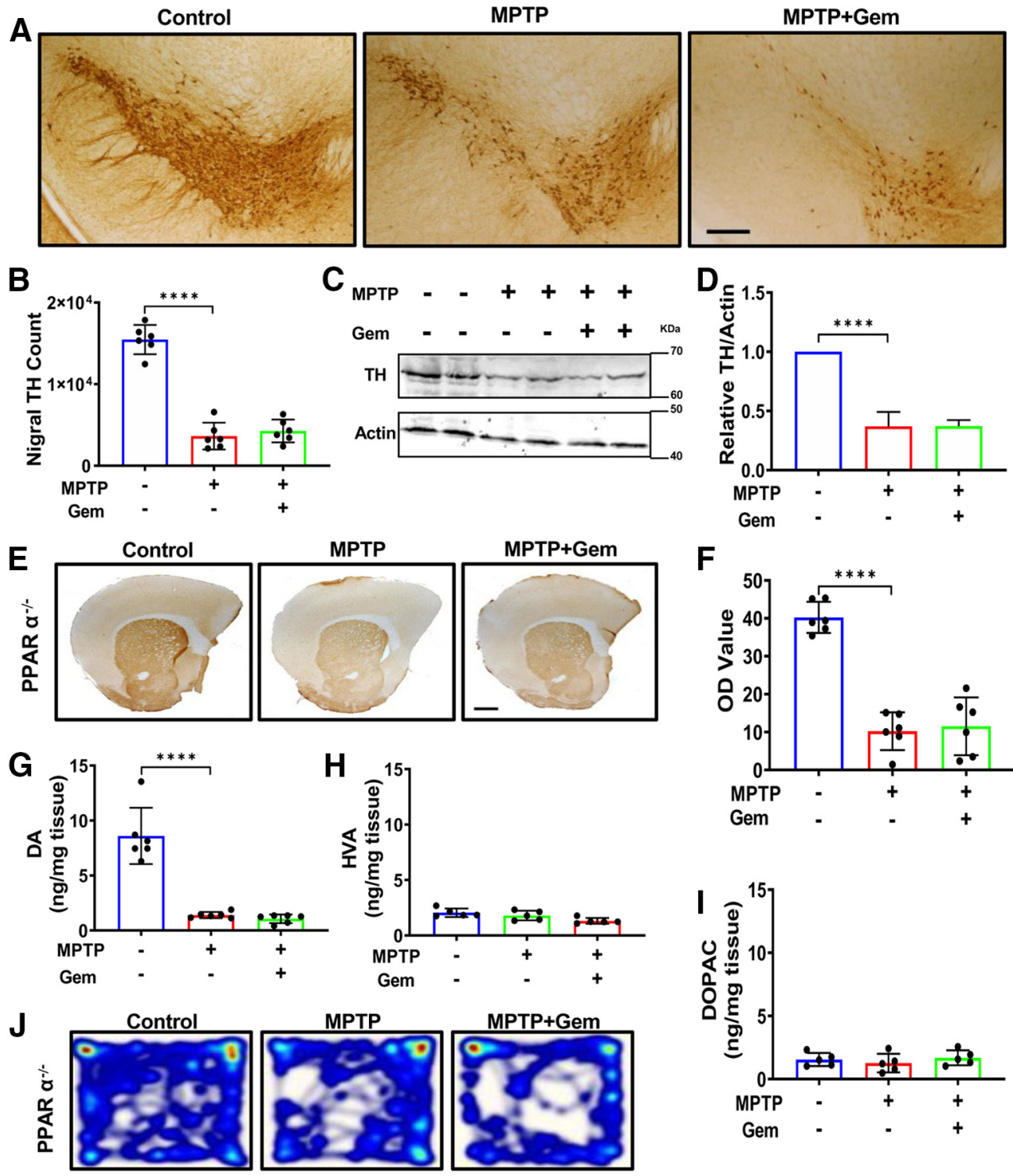

$\mathbf{F}$
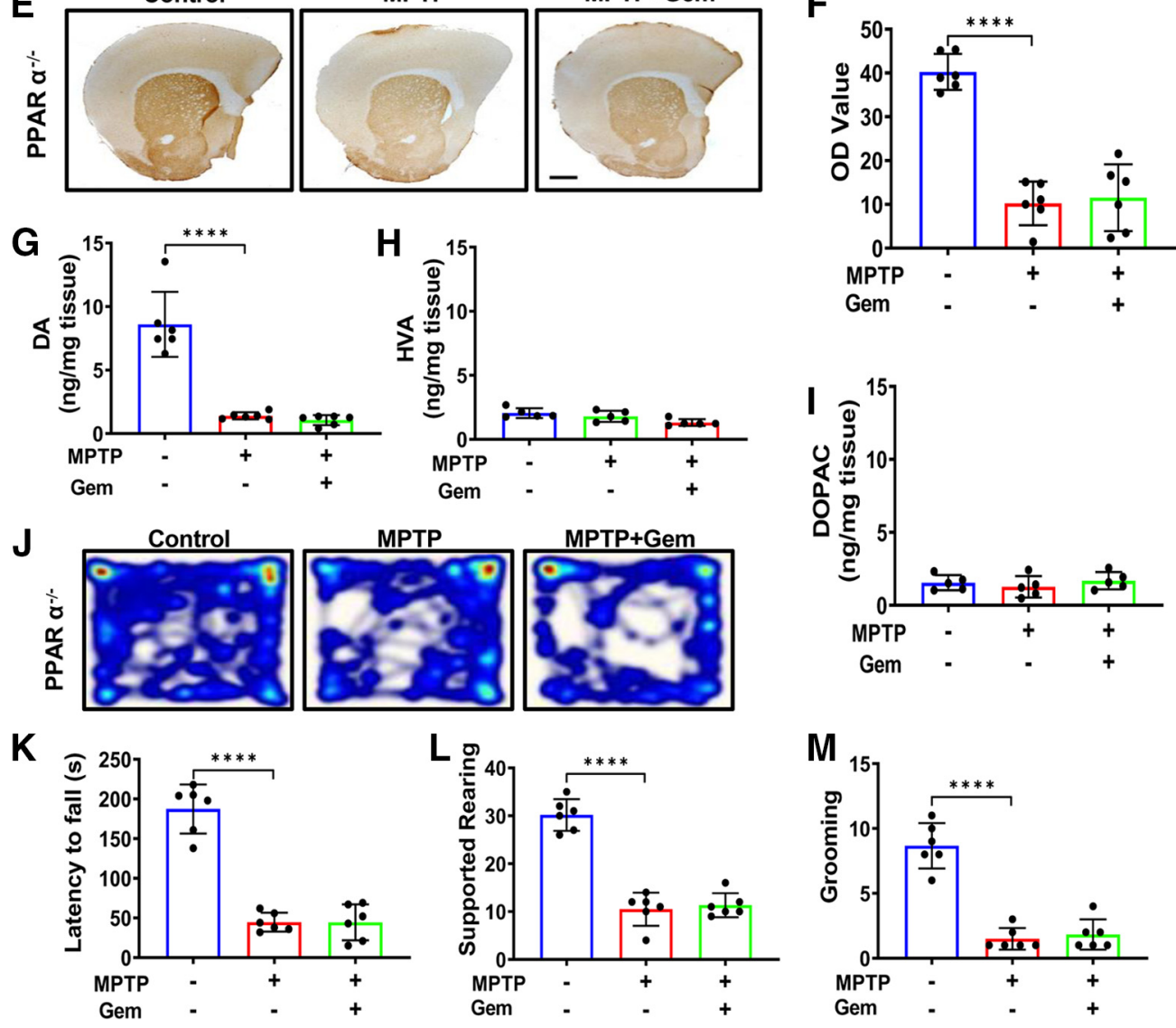

Figure 3. Gemfibrozil (Gem) rescues nigrostriatal pathology in MPTP intoxicated mice via PPAR $\alpha$. The 6 - to 8-week-old litter-matched PPAR $\alpha^{-1-}$ animals ( $n=6$ per group) were lesioned with MPTP ( $20 \mathrm{mg} / \mathrm{kg}$ body weight/injection, four intraperitoneal injections at every $2 \mathrm{~h}$ interval). At $4 \mathrm{~h}$ following the last MPTP injection, mice were fed gemfibrozil (7.5 mg/kg body weight/ d) via oral gavage for $7 \mathrm{~d}$. $\boldsymbol{A}, \boldsymbol{B}$, Representative TH immunostaining $(\boldsymbol{A})$, and stereological counting $(\boldsymbol{B})$ of nigral TH neurons. Results are the mean \pm the SEM of six animals per group with the significance of the mean tested by one-way ANOVA $\left(F_{(2,15)}=101.5>F_{c}=3.68 ; * * * * p<0.0001\right)$, followed by a post hoc Sidak's test that results in $* * * * p<0.0001$ for control versus MPTP, and $p=0.756$ for MPTP versus MPTP + Gem. $\boldsymbol{C}$, $\boldsymbol{D}$, TH protein level in the nigra was visualized via immunoblot $(\boldsymbol{C})$ and quantified using densitometric analysis $(\boldsymbol{D})$. $\boldsymbol{E}$, Results are the mean \pm SEM of three independent immunoblots with significance of the mean tested by one-way ANOVA $\left(F_{(2,6)}=68.84>F_{\mathrm{c}}=5.14 ; * * * * p<0.0001\right)$. followed by a post hoc Sidak's test that results in $* * * * p<0.0001$ for control versus MPTP, and $p=0.7556$ for MPTP versus MPTP $+G e m$. $F$, Representative immunostaining to visualize TH fiber expression in the striatum and corresponding optical density analyses. Results are the mean $\pm \mathrm{SEM}$ of six level-matched striatal sections per animal. Significance of the mean was tested by a one-way ANOVA $\left(F_{(2,15)}=\right.$ $\left.51.88>F_{\mathrm{c}}=3.68 ; * * * * p<0.0001\right)$, followed by a post hoc Sidak's test that results in $* * * * p=0.0001$ for control versus MPTP and $p=0.918$ for MPTP versus MPTP + Gem. G-I, Analysis of dopamine $(D A ; G), H V A(\boldsymbol{H})$, and DOPAC $(\boldsymbol{I})$ in striatum. Results are the mean \pm SEM of six animals per group with significance of the mean tested by one-way ANOVA $\left(F_{(2,15)}=\right.$ $48.27>F_{\mathrm{c}}=3.89 ; * * * * p<0.0001$ ), followed by a post hoc Sidak's test that results in $* * * * p<0.0001$ for control versus MPTP, and $p=0.910$ for MPTP versus MPTP + Gem. $J$, Representative heat map tracing taken from the open field analysis assessing locomotive behavior. $\boldsymbol{K}$, Rotarod analysis measuring latency to fall in seconds. Results are the mean \pm SEM of six animals per group, with the significance of the mean tested by one-way ANOVA $\left(F_{(2,15)}=75.77>F_{c}=3.89 ; * * * * p<0.0001\right)$, followed by a post hoc Sidak's test that results in $* * * * p<0.0001$ for control versus MPTP, and $p>0.9999$ for MPTP versus MPTP + Gem. $L$, Supported rearing counts; one-way ANOVA $\left(F_{(2,15)}=76.42>F_{\mathrm{c}}=3.89 ; * * * * p<0.0001\right)$, 
as a template during PCR. The $5^{\prime}$ flanking sequence of the mouse $G d n f$ $(-760 /+47)$ gene was isolated by PCR. Primers were designed from gene bank sequences (sense: $5^{\prime}$-acgcgtGAGGGAGGGCAAGTGTGT TTCCACCAAG-3'; antisense: $5^{\prime}$-agatctGCGGTGTGGAGCAACA CCAGGCAGACA- $3^{\prime}$ ). The sense primer was tagged with the Mlu1 restriction enzyme, while the antisense primer was tagged with BglII. The PCR was performed using an Advantage-2 PCR Kit (Clontech) according to the manufacturer instruction. The resulting fragments were gel purified and ligated into the PGEM-TEasy Vector (Promega). These fragments were further subcloned into the PGL-3 Enhancer Vector after digestion with corresponding restriction enzymes and verification by sequencing in the automated sequencer (Functional Biosciences).

Assay of GDNF promoter-driven luciferase activity. Astrocytes plated at $50-60 \%$ confluence in 12 -well plates were transfected with $0.25 \mu \mathrm{g}$ of pGdnf1-Luc using Lipofectamine Plus (Thermo Fisher Scientific). After $24 \mathrm{~h}$ of transfection, cells were stimulated with different concentrations of gemfibrozil under serum-free condition for $4 \mathrm{~h}$. Firefly luciferase activities were analyzed in cell extracts using the luciferase assay system kit (Promega) in a TD-20/20 Luminometer (Turner Designs), as described previously (Jana et al., 2007; Gottschalk et al., 2019).

Rotarod test. The motor coordination of the mice was examined using the Rotarod apparatus (catalog \#ENV-576 M, Med Associates), using a protocol described previously (Ghosh et al., 2007). Briefly, before the acquisition of data, the Rotarod system was carefully checked to ensure that its automatic fall sensor, the start speed, and acceleration protocols were properly functioning. Each mouse was placed on the confined (gated) section of the rod, and the trial was initiated with a smooth ramped speed increase from 4 to $40 \mathrm{rpm}$ for $5 \mathrm{~min}$. A mouse that failed to fall off the rod after $5 \mathrm{~min}$ was manually removed. Latency to fall was measured in seconds and was used to determine motor coordinator status.

Open field test. The open field test was completed to determine spontaneous exploratory activity and stress-related behavior in an open field environment. Before the acquisition of data, each mouse was able to freely explore the square $40 \times 40 \mathrm{~cm}$ square arena with walls $30 \mathrm{~cm}$ high and a wooden floor for $5 \mathrm{~min}$. A camera (GenICam, model acA1300$60 \mathrm{gm}$, Basler) connected to a Noldus computer software was suspended above the open field arena. Each mouse was placed in the center of the arena, and locomotor activity and stereotypical behaviors (rearing and grooming) were monitored for $5 \mathrm{~min}$ using live video tracking (Noldus).

Statistical analysis. All of the statistical analyses were conducted using GraphPad Prism version 8.2c software. Unless otherwise noted, one-way or two-way ANOVA followed by Tukey's analyses was performed to determine the significance of differences among multiple experimental groups. Post hoc Sidak's pairwise comparisons were also used to compare pairs of data between control (no lesion) and MPTP (lesion alone), and MPTP and MPTP + gemfibrozil (lesion and treatment). Data are expressed as the mean \pm SEM, and values with $p<0.05$ were considered statistically significant.

\section{Results}

Gemfibrozil rescues nigrostriatal pathology and motor deficits in the MPTP-insulted mouse model of PD

We examined the effect of gemfibrozil on the nigrostriatal pathology and motor deficits in the MPTP mouse model of PD. An even sex distribution of litter-matched C57BL/6 mice $(n=6 /$ group) were randomly assigned into the following three separate groups: control (no lesion); MPTP (lesion alone); and MPTP plus gemfibrozil (lesion plus treatment). Four hours following

followed by post hoc Sidak's test resulting in $* * * * p<0.0001$ for control versus MPTP, and $p=0.8774$ for MPTP versus MPTP + Gem. $M$, Grooming counts; one-way ANOVA $\left(F_{(2,15)}=\right.$ $\left.57.37>F_{\mathrm{c}}=3.89 ; * * * * p<0.0001\right)$, followed by post hoc Sidak's test resulting in $* * * * p<0.0001$ for control versus MPTP, and $p=0.8879$ for MPTP versus MPTP + Gem. the last injection, mice were treated with gemfibrozil $(7.5 \mathrm{mg} / \mathrm{kg} / \mathrm{d})$ via gavage for $7 \mathrm{~d}$ followed by evaluation of $\mathrm{TH}$ expression in the SNPc via immunohistochemistry. Interestingly, we found that MPTP intoxication drastically reduced TH nigral counts compared with control animals, whereas oral administration of gemfibrozil displayed a significant rescue of nigral TH cells (Fig. 1A,B). The same results were seen in nigral lysate tissue visualized via immunoblot followed by densitometric analysis (Fig. 1C,D). Next, we quantified TH fiber density and neurotransmitter concentrations in the striatum. Gemfibrozil treatment significantly rescued striatal TH fiber density (Fig. 1E) and dopamine concentrations (Fig. 1G), suggesting that gemfibrozil treatment not only protected nigral pathology, but also restored the striatal deficits after MPTP intoxication. Finally, we found that animals in the gemfibrozil treatment group showed significant improvement in locomotive activity (Fig. $1 J$ ), and in the frequency of supported rearing (Fig. $1 L$ ) and grooming (Fig. $1 M$ ), indicating a functional improvement in activities mediated by the striatum. In addition, treatment with gemfibrozil significantly improved motor coordination as measured by rotarod (Fig. $1 \mathrm{~K}$ ). Together, these results suggest that gemfibrozil protects the nigrostriatum and improves locomotor activities in the MPTP mouse model of PD.

\section{Gemfibrozil rescues nigrostriatal pathology in MPTP- intoxicated mice via PPAR $\alpha$}

Given that gemfibrozil is a known agonist of $\operatorname{PPAR} \alpha$, we decided to test whether PPAR $\alpha$ activity might be linked to the protection provided by gemfibrozil treatment in the MPTP mouse model of PD (Roy and Pahan, 2009). To test this, we assessed nigral expression of PPAR $\alpha$ protein in 6- to 8-week-old WT animals (Fig. 2A). Based on our mean fluorescence intensity (MFI) analysis (Fig. $2 B$ ), we identified that MPTP-intoxicated animals had significantly reduced levels of PPAR $\alpha$ compared with controls; however, MPTP-intoxicated animals treated with gemfibrozil displayed significant rescue of nigral PPAR $\alpha$ expression (Fig. 2A). Our immunofluorescence findings were corroborated by immunoblot of nigral lysates for PPAR $\alpha$ (Fig. 2C,D).

To test whether the protection from gemfibrozil requires the presence of PPAR $\alpha$ in vivo, $\operatorname{PPAR} \alpha$-null $\left(\operatorname{PPAR} \alpha^{-1-}\right)$ mice ( $n=6 /$ group) were intoxicated with MPTP. Strikingly, unlike WT animals, gemfibrozil treatment provided no significant protection of nigral TH cells, as evident by both nigral TH cell counts (Fig. 3B) and immunoblot analysis of nigral lysate tissues followed by densitometric evaluation (Fig. $3 C, D$ ). In addition, gemfibrozil treatment neither protected striatal TH fibers (Fig. $3 E$ ) nor rescued dopamine, as measured by HPLC (Fig. $3 G$ ). Finally, gemfibrozil did not provide any significant improvement in gross motor activity in MPTP-treated PPAR $\alpha$-null animals (Fig. $3 J$ ) or improve motor coordination, as measured on the rotarod test (Fig. $3 \mathrm{~K}$ ). No significant improvement was observed in unsupported rearing or grooming activities (Fig. $3 L, M$ ). Together, these results suggest that gemfibrozil requires PPAR $\alpha$ to protect the nigrostriatal pathology observed in the MPTP mouse model of PD.

\section{Gemfibrozil upregulates astroglial GDNF via PPAR $\alpha$}

Multiple reports have identified that PPAR $\alpha$ can modulate the expression of genes at the level of transcription from both neurons and glia in vivo (Berger et al., 2005). Considering that MPTP intoxication acutely destroys dopaminergic neurons 
irreversibly, we investigated whether the gemfibrozil-mediated protection in WT animals, but not in PPAR $\alpha^{-l-}$ animals, was derived from a non-neuronal source. To test this possibility, astrocytes were isolated from WT and $\operatorname{PPAR} \alpha^{-/}$

2- to 3-d-old pups, as described previously (Prorok et al., 2019), and treated with increasing concentrations of gemfibrozil ( $\mu \mathrm{M})$ under serum-free conditions, followed by analyzing $G d n f$ mRNA expression using real-time PCR. A significant increase in $G d n f$ mRNA was observed in WT astrocytes (Fig. 4A), but not PPAR $\alpha$-null astrocytes (Fig. $4 B$ ), with maximal expression observed at a $15 \mu \mathrm{M}$ concentration of gemfibrozil. Next, we tested GDNF protein expression from both WT and PPAR $\alpha^{-l-}$ astrocytes under similar treatment conditions Again, a significant increase in GDNF protein expression was observed in WT (Fig. 4C), but not PPAR $\alpha^{-1-}$ (Fig. 4D), primary astrocytes treated with gemfibrozil. To understand the specificity of antiGDNF antibody, we performed CRISPR-mediated editing of Gdnf gene in mouse astrocytes followed by Western blotting with antiGDNF antibody (catalog \#AB5252, Millipore). As evident from Figure 4G, CRISPR editing markedly reduced the level of GDNF compared with GFP control, indicating the specificity of the anti-GDNF antibody used in this study. Immunofluorescence staining double labeling primary astrocytes with GFAP (cy-3) and GDNF (cy-3) from both WT (Fig. $4 H$ ) and PPAR $\alpha^{-/-}$(Fig. $4 I$ ) corroborated indeed that gemfibrozil stimulated the upregulation of WT, but not $\operatorname{PPAR} \alpha$-null primary astrocytes.

Next, we wanted to study whether $\operatorname{PPAR} \alpha$ was directly involved in the transcription of the Gdnf gene expressed in astrocytes. To study this, we first performed a promoter analysis of $G d n f$ mRNA. Interestingly, our analysis identified that the Gdnf promoter harbors a consensus PPRE spanning positions -522 to -500 (Fig. $5 G)$ upstream of the transcription start site, suggesting that $\operatorname{PPAR} \alpha$ could be directly recruited to the Gdnf promoter. To investigate this, we completed a ChIP assay using primers designed to span $110 \mathrm{bp}$ of the PPRE site of $G d n f$. Following immunoprecipitation of gemfibrozil-treated astrocytic chromatin fragments with antibodies against $\operatorname{PPAR} \alpha, \operatorname{PPAR} \beta$, and $\operatorname{PPAR} \gamma$, we successfully amplified product in $\operatorname{PPAR} \alpha$-immunoprecipitated fractions, but not $\operatorname{PPAR} \beta$ - or PPAR $\gamma$-immunoprecipitated fractions (Fig. $5 B-D$ ), suggesting that $\operatorname{PPAR} \alpha$ is directly associated with the $G d n f$ promoter. Consistent with the recruitment of $\operatorname{PPAR} \alpha$ to the PPRE site, gemfibrozil was also able to recruit RNA polymerase to the Gdnf gene promoter (Fig. 5E). These results are specific as no product amplification was observed in immunoprecipitants with control IgG (Fig. $5 F)$. These results indicate that gemfibrozil stimulates the recruitment of $\operatorname{PPAR} \alpha$ to the
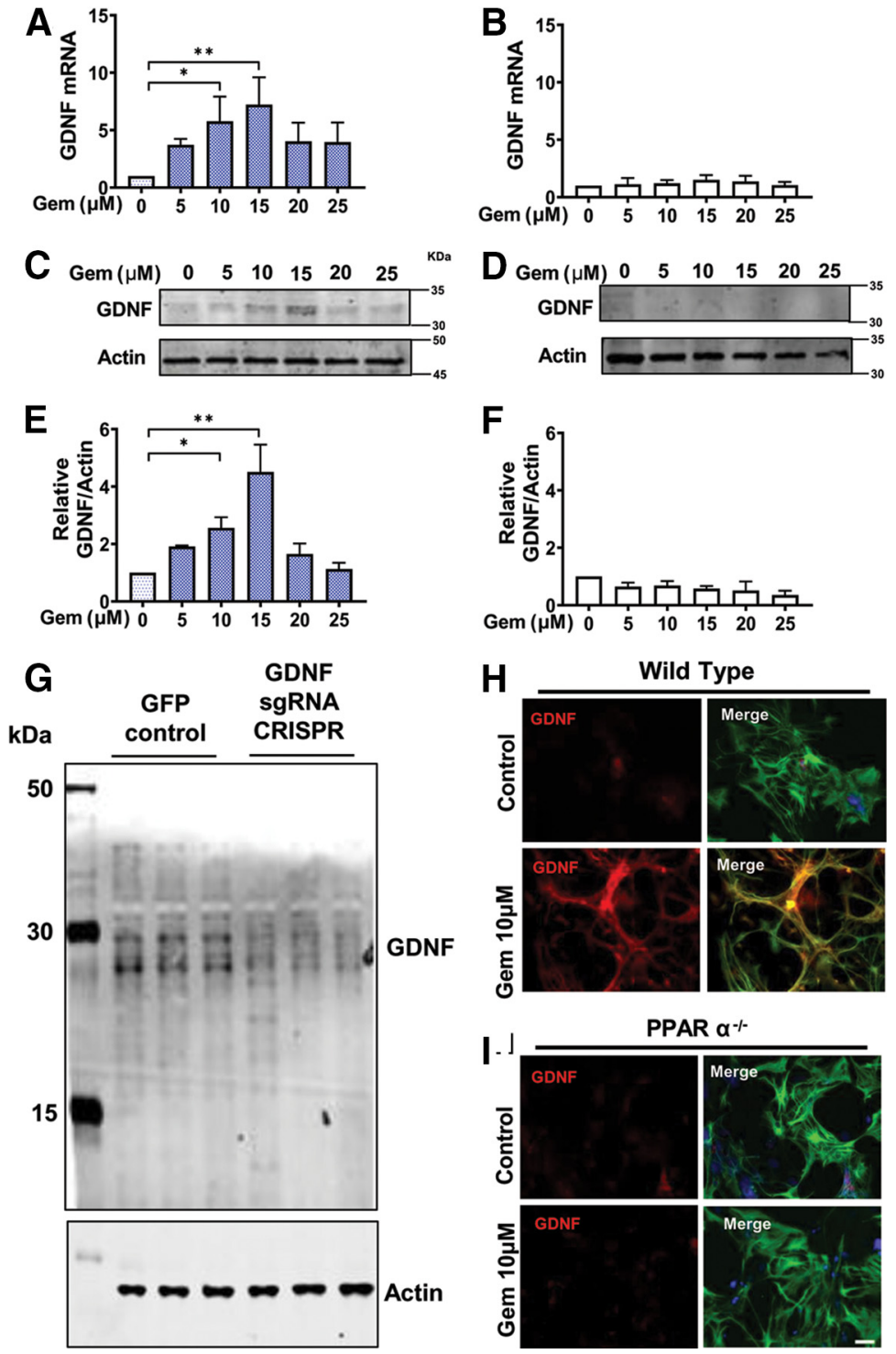

Figure 4. Gemfibrozil upregulates the expression of Gdnf via PPAR $\alpha^{-/-}$in mouse primary astrocytes. Primary astrocytes isolated from 2- to 3-d-old pups from both genotypes were treated with increasing concentrations of gemfibrozil ( $\mu \mathrm{M})$ for $2 \mathrm{~h}$ under serum-free conditions followed real-time PCR analysis to assess Gdnf mRNA expression. $\boldsymbol{A}$, WT astrocytes. Results are the mean $\pm S D$ of three independent experiments, and the significance of the mean was tested by one-way ANOVA $\left(F_{(5,12)}=4.916>F_{\mathrm{c}}=3.68 ; * p=0.0112\right)$. A post hoc Tukey's test results in $* p=0.015$ for $10 \mu \mathrm{m}$ gemfibrozil versus control, and $* * p=0.002$ for $15 \mu \mathrm{m}$ gemfibrozil versus control. $\boldsymbol{B}$, PPAR $\alpha^{-1-}$ astrocytes. Results are the mean \pm SD of three independent experiments. Significance of the mean was tested by one-way ANOVA but found no significant differences among the means $\left(F_{(5,12)}=0.8125<F_{\mathrm{c}}=\right.$ $3.68 ; p=0.562)$. C, $\boldsymbol{D}$, Cells were treated with gemfibrozil for $18 \mathrm{~h}$ under serum-free conditions followed by monitoring GDNF in WT astrocytes by immunoblotting $(\boldsymbol{C})$ that was quantified via densitometric analyses $(\boldsymbol{D})$. Results are the mean \pm the SEM of three independent immunoblots. Significance of the mean tested by one-way ANOVA $\left(F_{(5,12)}=24.59>F_{c}=3.68\right)$. A post hoc Tukey's test results in $* * p=0.0049$ for $10 \mu \mathrm{m}$ gemfibrozil versus control for $15 \mu \mathrm{m}$ gemfibrozil versus control. $\boldsymbol{E}, \boldsymbol{F}, \mathrm{GDNF}$ expression in PPAR $\alpha^{-1-}$ astrocytes was visualized by immunoblotting $(\boldsymbol{E})$ and quantified via densitometric analyses $(\boldsymbol{F})$. Results are the mean $\pm S D$ of three independent immunoblots and the significance of the mean was tested by one-way ANOVA $\left(F_{(5,12)}=4.695>F_{c}=3.68 ; * p=0.0132\right)$. A post hoc Tukey's test was used to find significant differences among the treatment groups and shows a significant reduction of GDNF protein compared with control at doses of $15 \mu \mathrm{m}$ in PPAR $\alpha^{-1-}$ primary astrocytes. G, Mouse primary astrocytes were infected with GFP-control lentivirus and mouse GDNF sgRNA CRISPR all-in-one lentivirus $\left(6 \times 10^{6} \mathrm{IU} / \mathrm{ml}\right)$ according to manufacturer protocol and $2 \mathrm{~d}$ after infection, the level of GDNF protein was monitored in cells by Western blot. Actin was run as a loading control. Results represent CRISPR editing of three different wells. $\boldsymbol{H}, \boldsymbol{I}$, Protein expression levels were corroborated by double labeling WT $(\boldsymbol{H})$ and PPAR $\alpha^{-I-}(\boldsymbol{I})$ astrocytes with antibodies to GDNF (cy-5) and GFAP (cy-3). DAPI was used to visualize the nucleus. Scale bar, $20 \mu \mathrm{m}$. 

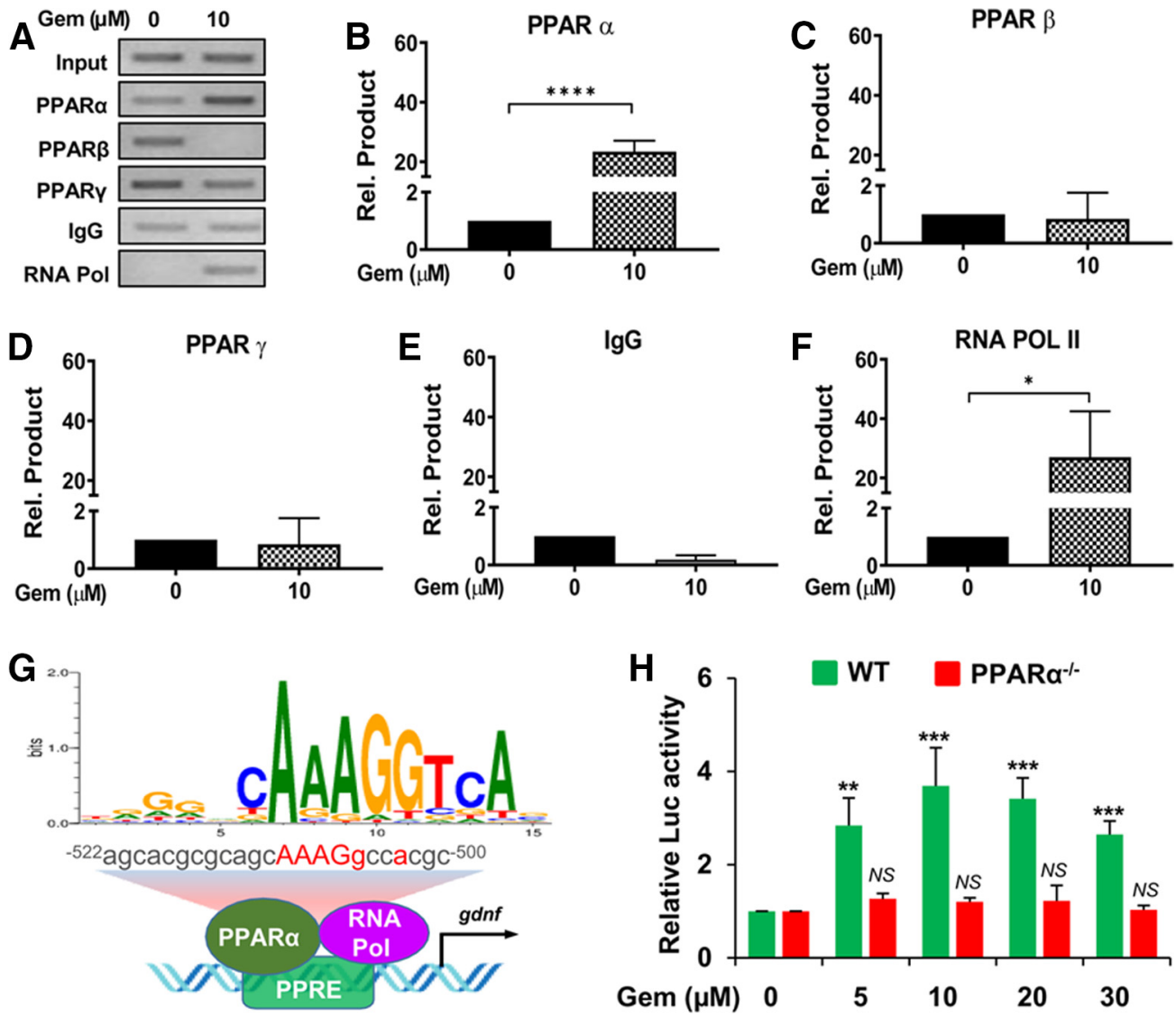

Figure 5. Gemfibrozil induces the recruitment of PPAR $\alpha$, but neither PPAR $\beta$ nor PPAR $\gamma$, to the Gdnf gene promoter and stimulates Gdnf promoter-driven reporter activity in astrocytes via PPAR $\alpha$. $\boldsymbol{A}-\boldsymbol{F}$, Primary astrocytes were treated with $10 \mu \mathrm{m}$ gemfibrozil for $2 \mathrm{~h}$ followed by ChIP followed by $\mathrm{PCR}(\boldsymbol{A})$ and real-time PCR $(\boldsymbol{B}-\boldsymbol{F})$. Results are the mean \pm SEM of three independent experiments. An ANOVA shows $\left(F_{(5,18)}=15.11>F_{c}=2.97 ; * * * * p<0.0001\right)$. Post hoc unpaired $t$ tests indicate a significant difference in samples incubated with antibodies to both PPAR $\alpha(t=12.076$; $* * * * p<0.0001)$ and RNA polymerase II $(t=3.536 ; * p=0.0154)$. $\mathbf{G}$, A schema depicts a detailed map of the promoter analysis of the Gdnf gene. The map reveals a conserved PPRE in the promoter of the Gdnf gene at -500 to -522 upstream of the Gdnf start site on chromosome 15. H, Astrocytes isolated from wild-type and PPAR $\alpha^{-l-}$ mice were transfected with pGdnf1-Luc for $24 \mathrm{~h}$ followed by treatment with different concentrations of gemfibrozil for $4 \mathrm{~h}$ before luciferase assay. $* * p<0.01$ and $* * * p<0.001$ versus control. NS, Not significant.

$G d n f$ promoter to induce the transcription of Gdnf gene (Fig. $5 G)$. To further confirm the involvement of $\operatorname{PPAR} \alpha$ in the transcription of Gdnf, we cloned the Gdnf promoter containing the PPRE into the pGL3 Enhancer vector. Induction of Gdnf promoter-driven luciferase activity in wild-type astrocytes, but not PPAR $\alpha^{-1-}$ astrocytes, by different doses of gemfibrozil (Fig. 5H) clearly indicates an important role of $\operatorname{PPAR} \alpha$ in gemfibrozil-mediated transcription of $G d n f$ gene in astrocytes.

Next, to test this system in vivo, we assessed nigral GDNF expression via immunofluorescence double-labeling nigral sections for GDNF (cy-5) and GFAP (cy-3) from both WT and PPAR $\alpha^{-1-}$ mice ( $n=6 /$ group). Remarkably, our immunofluorescence staining indicated that treatment with gemfibrozil induced a significant upregulation of GDNF expression in WT MPTP-lesioned mice, compared with the MPTP-lesioned group alone (Fig. 6A). Unlike WT mice, however, PPAR $\alpha^{-1-}$ mice showed no significant upregulation of GDNF following treatment with gemfibrozil (Fig. $6 B$ and $6 F$ ). These findings were corroborated using nigral lysate tissue from WT and $\mathrm{PPAR}^{-1-}$ mice with GDNF expression visualized via immunoblot followed by relative densitometry (Fig. 6C-E). Together, these results suggest that $\mathrm{PPAR} \alpha$ modulates the expression of GDNF released by astrocytes and, by doing so, supports the health of dopaminergic neurons in the MPTP mouse model of PD.
Gemfibrozil protects the nigrostriatal pathway and alleviates motor deficits via astroglial GDNF

To test the relevance of gemfibrozil-mediated stimulation of astroglial-derived GDNF in vivo, we generated transgenic mice (Fig. 7A) lacking astrocyte-specific $G d n f\left(G d n f^{\Delta a s t r o}\right)$, with agematched control littermates $\left(G f a p^{c r e}\right)$ included as controls. Double-label immunofluorescence analysis of GFAP and GDNF showed a loss of astroglial GDNF in Gdnf ${ }^{\Delta a s t r o}$ mice, but not in $G f a p^{\text {cre }}$ mice (Fig. $7 B$ ). Following the acute MPTP intoxication protocol and gemfibrozil treatment within the study groups, we evaluated TH expression (Fig. 7C) in the SNPc via stereological counting (Fig. 7D). Compared with nonlesioned control animals, both Gfap ${ }^{\text {cre }}$ and Gdnf $f^{\Delta a s t r o}$ mice lesioned with MPTP displayed a significant reduction in TH cell numbers; however, gemfibrozil treatment in $G f a p^{c r e}$ mice lesioned with MPTP significantly rescued TH expression compared with gemfibrozil-treated $G d n f^{\Delta a s t r o}$ mice (Fig. $7 E$ ). This pattern of rescue observed in Gfap ${ }^{\text {cre }}$ mice, but not in Gdnf $f^{\Delta a s t r o}$ mice, was corroborated by examining $\mathrm{TH}$ protein expression in nigral lysate visualized on immunoblot (Fig. $7 F-H$ ). In addition to nigral protection, we found that gemfibrozil-treated $G f a p^{\text {cre }}$ mice, but not Gdnf $f^{\Delta a s t r o}$ mice, displayed a significant rescue striatal TH fiber density (Fig. $7 H, I)$ and a near normalization of striatal dopamine concentrations measured via HPLC (Fig. 8A). Finally, latency to fall, in seconds, as measured on the rotarod apparatus, was significantly increased in gemfibrozil-treated MPTP-intoxicated Gfap ${ }^{\text {cre }}$ mice 
A

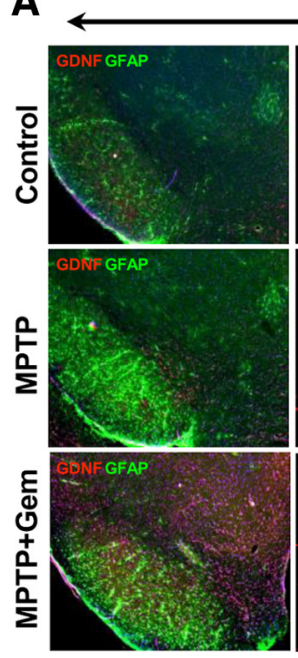

B
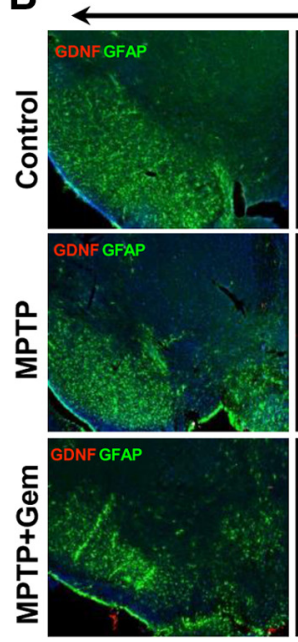

Wild Type

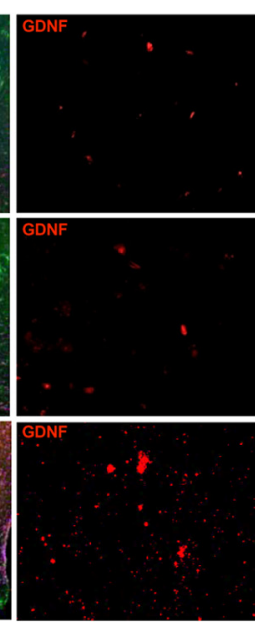

PPAR $\alpha$

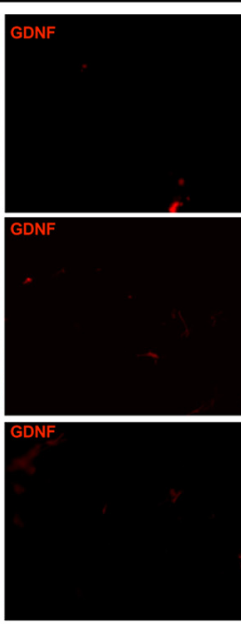

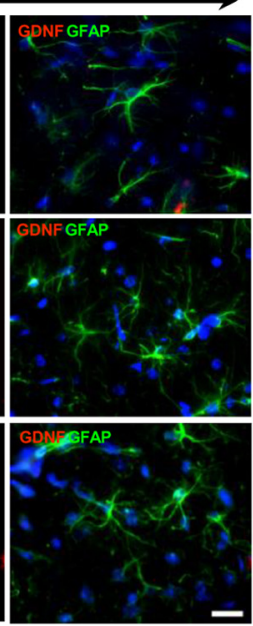

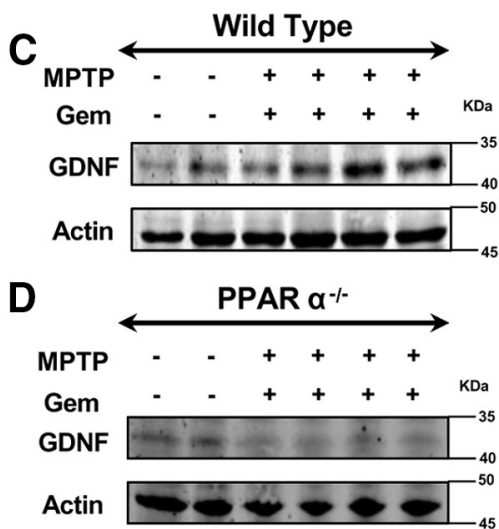

E
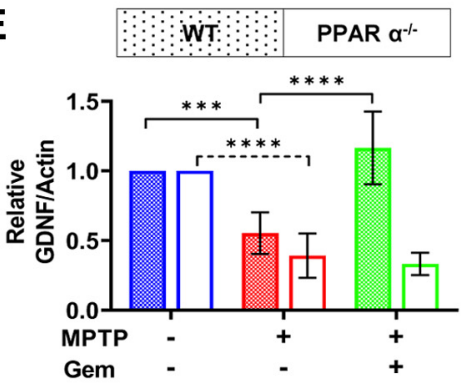

$\mathbf{F}$

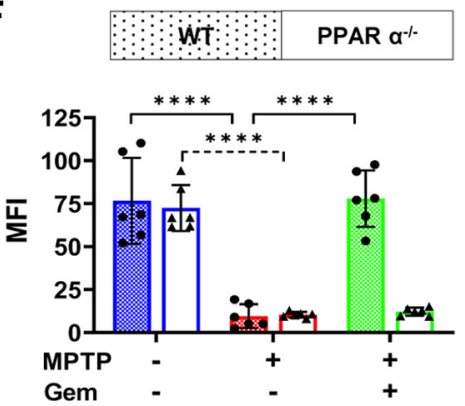

Figure 6. Gemfibrozil (Gem) upregulates astroglial GDNF via PPAR $\alpha^{-1-}$. The 6- to 8-week-old WT and PPAR $\alpha^{-1-}$ mice ( $n=6 / \mathrm{group}$ ) were lesioned with MPTP (20 mg/kg body weight/ injection, four intraperitoneal injections every $2 \mathrm{~h}$ ). At $4 \mathrm{~h}$ following the last MPTP injection, mice were fed gemfibrozil (7.5 mg/kg body weight/d) via oral gavage for $7 \mathrm{~d}$. $\boldsymbol{A}, \boldsymbol{B}$, Nigral sections isolated from WT $(\boldsymbol{A})$ and PPAR $\alpha^{-1-}(\boldsymbol{B})$ mice were double labeled for GFAP (cy-3) and GDNF (cy-5). DAPI was used to visualize the cell nuclei. Scale bar, $50 \mu$ m. $\boldsymbol{C}$, $\boldsymbol{D}, \boldsymbol{F}$, Nigral tissue isolated from WT $(\boldsymbol{C})$, and PPAR $\alpha^{-l-}(\boldsymbol{D})$ animals was used to assess the pattern of GDNF expression via immunoblot and quantified using densitometric analyses shown in $\boldsymbol{F}$. Results are the mean \pm SD of three independent immunoblots. A two-way ANOVA results in $\left(F_{(2,11)}=41.07>F_{c}=3.31 ; * * * p<0.0001\right)$ for genotype and $\left(F_{(2,11)}=48.68>F_{c}=3.31 ; * * * p<0.0001\right)$ for treatment. $\boldsymbol{E}, \boldsymbol{F}, \mathrm{MFI}$ values were calculated to quantify GDNF expression from WT $(\boldsymbol{E})$ and PPAR $\alpha^{-1-}(\boldsymbol{F})$ animals. GDNF MFI measurements were preformed from serial sections isolated from $n=6$ mice/group and averaged. A two-way ANOVA results in $F_{(2,11)}=66.84>F_{c}=3.31(* * * p<0.0001)$ for genotype and $F_{(2,11)}=25.44>F_{c}=4.17(* * * p<0.0001)$ for treatment. Post hoc Sidak's multiple-comparisons tests were used to identify significant differences among the control, MPTP, and MPTP + Gem groups ( $* * * * p<0.0001)$ and are represented on the figure.

compared with their $G d n f^{\Delta}$ astro littermates, as were gross motor locomotive activities (Fig. 8E) and measurements of stereotypic behaviors, including supported rearing (Fig. $8 F$ ) and grooming (Fig. 8G). Together, this in vivo study clarifies the role of astroglial GDNF as it pertains to the protection against the nigrostriatal damage observed in the MPTP model of PD.

\section{Discussion}

$\mathrm{PD}$ is a devastating neurodegenerative disorder of the midbrain dopaminergic neurons that supply dopamine to the striatum. A reduction in striatal dopamine concentrations results in the cardinal motor symptoms of the disorder. Despite intense investigations, no effective therapy is available to halt the progression of PD. Gemfibrozil is an FDA-approved lipid-lowering drug, and several lines of evidence presented in this article clearly demonstrate that gemfibrozil is capable of protecting dopaminergic neurons from parkinsonian toxicity. Our conclusion is based on the following. First, similar to PD, nigral THir neurons died and striatal THir fibers disappeared in MPTP-intoxicated mice. According to Tieu et al. (2003), a major part of MPTP could be converted into $\mathrm{MPP}^{+}$within $90 \mathrm{~min}$ of the last injection of MPTP. Therefore, to evade any likely effect of gemfibrozil on the entry and conversion of MPTP into $\mathrm{MPP}^{+}$in the brain, oral gemfibrozil treatment started from $4 \mathrm{~h}$ after the last injection of MPTP. Even with this paradigm, gemfibrozil protected TH-positive nigral dopaminergic neurons and $\mathrm{TH}$-positive striatal fibers from MPTP toxicity. However, to rule out the interference of gemfibrozil on MPTP metabolism, future studies could be performed to deliver the drug in a more delayed fashion followed by measuring MPP levels by HPLC. Second, as observed in PD, striatal level of neurotransmitters decreased in MPTP-intoxicated mice. But treatment with gemfibrozil restored the level of neurotransmitters. Third, gemfibrozil also ameliorated functional 

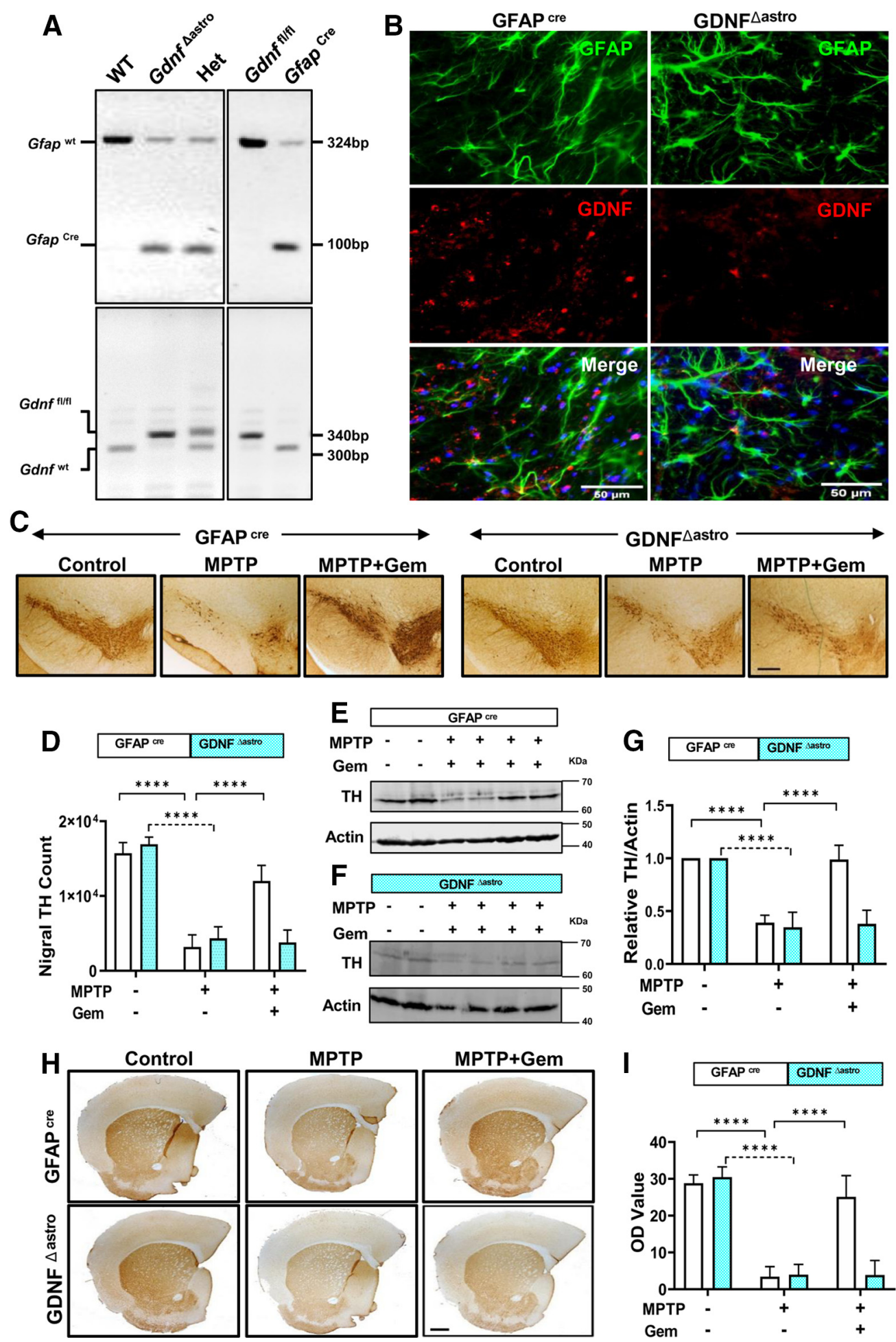

Figure 7. Gemfibrozil (Gem) protects the nigrostriatal pathway via astrocytic GDNF in the MPTP mouse model. $\boldsymbol{A}$, Genotyping of Gdnf ${ }^{\text {aastro }}$ (astrocyte-specific GDNF knock-out) mice. $\boldsymbol{B}$, Nigral sections of 6- to 8-week-old Gfap ${ }^{\text {cre }}$ mice or Gdnf ${ }^{\triangle a s t r o}$ mice were double labeled for GDNF and GFAP. Results represent the analysis of two sections of each of three mice per group. The 6- to 8-week-old Gfap ${ }^{\text {cre }}$ mice ( $n=6 /$ group) or Gdnf ${ }^{\Delta a s t r o}$ mice ( $n=6 / \mathrm{group}$ ) were lesioned with MPTP ( $20 \mathrm{mg} / \mathrm{kg}$ body weight/injection, four intraperitoneal injections at every $2 \mathrm{~h}$ interval). At $4 \mathrm{~h}$ following the last MPTP injection, mice were fed gemfibrozil $\left(7.5 \mathrm{mg} / \mathrm{kg}\right.$ body weight/d) via oral gavage for $7 \mathrm{~d}$. C, Representative TH immunostaining from both Gfap ${ }^{\text {cre }}$ (top) and Gdnf ${ }^{\Delta a s t r o}$ (bottom) mice. D, Stereological counting of nigral TH cells in Gfap ${ }^{\text {cre }}$ and Gdnf ${ }^{\Delta a s t r o}$ mice. A two-way ANOVA results in $F_{(2,30)}=197.4>F_{c}=3.31$ (*****p<0.0001) for treatment and $F_{(1,30)}=13.77>F_{c}=4.17$ for genotype. $\boldsymbol{E}-\boldsymbol{G}$, Representative immunoblots from nigral lysate tissue from Gfap ${ }^{\text {ree }}(\boldsymbol{E})$ and $\mathbf{G d n f}{ }^{\Delta a s t r o}(\boldsymbol{F})$ mice and corresponding densitometric analyses $(\boldsymbol{G})$. Results are the mean \pm SEM of three independent immunoblots. A two-way ANOVA was adopted to identify significant differences between treatment and genotype and found $F_{(2,30)}=$ $120.1>F_{\mathrm{c}}=3.31(* * * * p<0.0001)$ for treatment and $F_{(1,30)}=42.74>F_{\mathrm{c}}=4.17(* * * * p<0.0001)$ for genotype. $\boldsymbol{H}$, I, Representative striatal TH staining from both $G$ fapp ${ }^{\text {cre }}$ (top), and $G$ Gnf ${ }^{\triangle a s t r o}\left(\right.$ bottom) mice $(\boldsymbol{H})$ and corresponding optical density measurements to quantify striatal TH fiber density $(\boldsymbol{I})$. A two-way ANOVA found $F_{(2,30)}=157.5>F_{\mathrm{c}}=3.31$ for treatment and $F_{(1,30)}=28.03>F_{c}=4.17(* * * * p<0.0001)$. Post hoc Sidak's multiple-comparisons tests were used to identify significant differences among the control, MPTP, and MPTP + Gem groups $(* * * * p<0.0001)$ and are represented on the figure. 


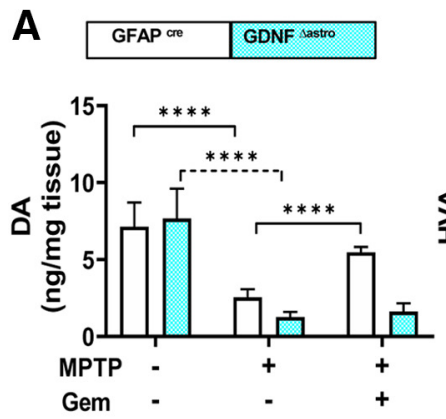

B

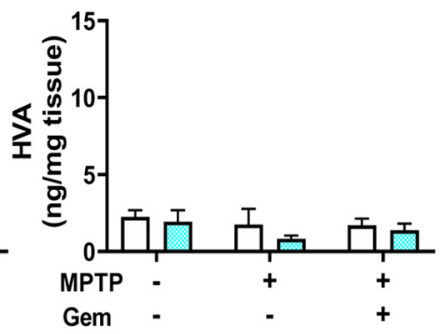

E

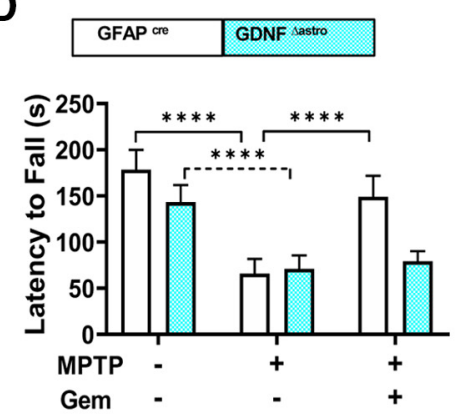

$\mathbf{F}$

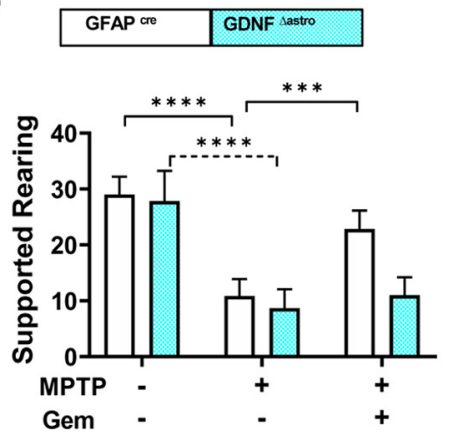

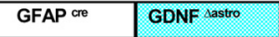

C
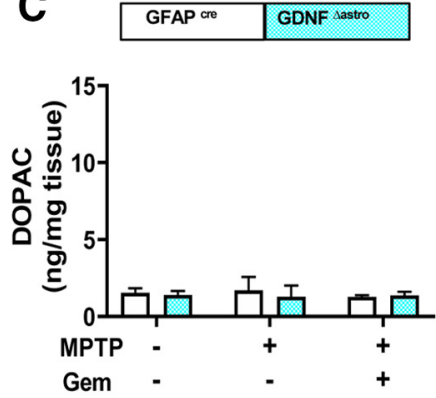

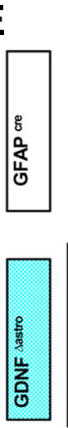

Control
MPTP

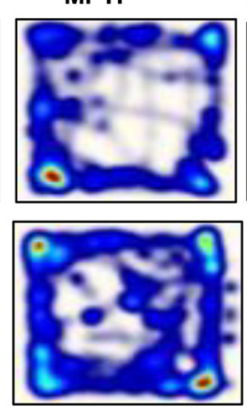

MPTP+Gem
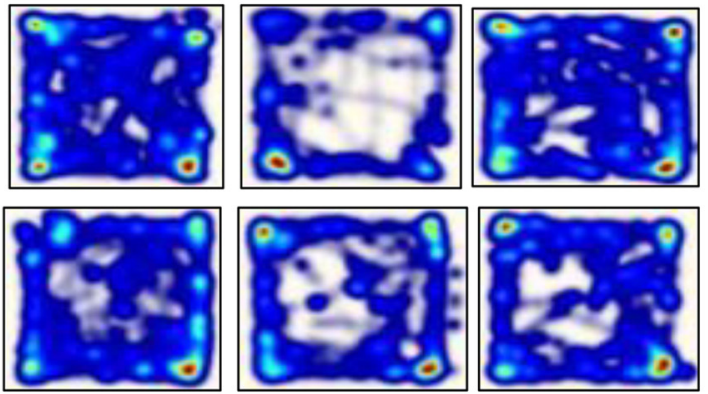

G \begin{tabular}{|l|l|}
\hline GFAP & Go \\
\hline
\end{tabular}

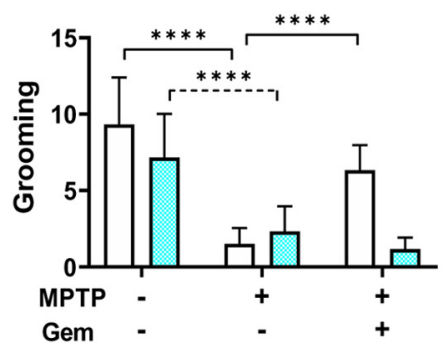

Figure 8. Gemfibrozil protects striatal catecholamine levels and restores behavioral function in MPTP-lesioned Gfap ${ }^{\text {cre }}$ mice, but not Gdnf ${ }^{\Delta a s t r o}$ mice. The 6- to 8-week-old Gfap ${ }^{\text {cre }}$ mice or $G d n f^{\triangle a s t r o}$ mice ( $n=6 /$ group) were lesioned with MPTP $(20 \mathrm{mg} / \mathrm{kg}$ body weight/injection, four intraperitoneal injections at every $2 \mathrm{~h}$ interval). $A-C$, At $4 \mathrm{~h}$ following the last MPTP injection, mice were fed gemfibrozil $(7.5 \mathrm{mg} / \mathrm{kg}$ body weight/d) via gavage for $7 \mathrm{~d}$. Analysis of dopamine (DA), DOPAC, and HVA in striatum. Results are the mean \pm SD of 6 mice/group. A two-way ANOVA found $F_{(2,30)}=82.08>F_{c}=3.13(* * * * p<0.0001)$ for genotype and $F_{(1,30)}=18.12>F_{c}=4.17(* * * p=0.0002)$ for treatment. $D$, Gfap ${ }^{\text {cre }}$ mice, but not Gdnf ${ }^{\text {aastro }}$ mice, displayed significant improvement with respect to motor coordination, as tested on Rotarod. A two-way ANOVA results in $F_{(2,30)}=80.40>F_{\mathrm{c}}=3.13$ (****p<0.0001) for treatment and $F_{(1,30)}=13.38>F_{c}=3.13(* * * * p<0.0001)$ for treatment. $\boldsymbol{E}$, Open field analysis. $\boldsymbol{F}$, Supported rearing. A two-way ANOVA results in $F_{(2,30)}=77.89>F_{c}=3.13(* * * * p<0.0001)$ for treatment and $F_{(1,30)}=16.84>F_{\mathrm{c}}=3.13(* * * * p<0.0001)$ for treatment. $G$, Grooming counts observed in the 5 min open field test. A two-way ANOVA results in $F_{(2,30)}=31.04>F_{\mathrm{c}}=$ $3.13(* * * * p<0.0001)$ for treatment and $F_{(1,30)}=10.29>F_{\mathrm{c}}=3.13(* * p=0.0032)$ for treatment. Post hoc Sidak's multiple-comparisons tests were used to identify significant differences among different groups $(* * * * p<0.0001)$.

impairment in MPTP-insulted mice. These results suggest that gemfibrozil may have implications in PD therapy.

Gemfibrozil is considered to be the prototype activator of $\operatorname{PPAR} \alpha$ (Roy and Pahan, 2009) and, by using this nuclear hormone receptor, is known to stimulate peroxisomal fatty acid $\beta$-oxidation in the liver (Smith et al., 2002; Zhang et al., 2019). Although gemfibrozil does not involve $\operatorname{PPAR} \alpha$ to suppress the expression of proinflammatory molecules in microglia (Jana et al., 2007; Jana and Pahan, 2012) and requires PPAR $\beta$ to increase the transcription of different myelin-specific genes (Jana et al., 2012), gemfibrozil mostly needs PPAR $\alpha$ for its biological functions (Ghosh et al., 2012, 2015; Corbett et al., 2015; Chandra and Pahan, 2019). Recently, we have seen that gemfibrozil requires $\operatorname{PPAR} \alpha$ to upregulate Nurr1 in dopaminergic neurons (Gottschalk et al., 2019) and that gemfibrozil also involves $\operatorname{PPAR} \alpha$ to lower cerebral plaque load and improve cognitive functions in a mouse model of $\mathrm{AD}$ via PPAR $\alpha$ (Chandra and Pahan, 2019). Therefore, in this article we also examined whether gemfibrozil required PPAR $\alpha$ to protect the nigrostriatum from parkinsonian toxicity. Decrease in PPAR $\alpha$ in the nigra of MPTPintoxicated mice, increase and/or restoration of $\operatorname{PPAR} \alpha$ in MPTP mouse model by gemfibrozil treatment, and the inability of gemfibrozil to protect dopaminergic neurons and striatal neurotransmitters in MPTP-intoxicated PPAR $\alpha^{-1-}$ mice clearly suggest that gemfibrozil requires $\operatorname{PPAR} \alpha$ to protect the nigrostriatum in the MPTP mouse model of PD.

How does gemfibrozil couple this lipid-lowering factor to nigrostriatal protection? GDNF is also considered to be a nigral trophic factor because of its positive effect on the survival and growth of dopaminergic neurons (Kordower et al., 2000; Burke, 2006; Dietz et al., 2006). Accordingly, a decrease in GDNF production in the brain has been shown to play an important role in nigrostriatal degeneration in PD (Howells et al., 2000; di Michele et al., 2003). We hypothesized whether PPAR $\alpha$ could be involved in the transcription of $G d n f$ in astrocytes. Indeed, we found that gemfibrozil displayed a significant upregulation of $G d n f$ mRNA 
and protein in primary astrocytes isolated from WT mice, but not PPAR $\alpha^{-1-}$ mice, and that gemfibrozil also induced the transcriptional activity of $G d n f$ promoter in astrocytes via $\operatorname{PPAR} \alpha$. Interestingly, we identified the presence of a PPRE in the Gdnf promoter and demonstrated that gemfibrozil treatment induced the recruitment of $\operatorname{PPAR} \alpha$, but neither $\operatorname{PPAR} \beta$ nor $\operatorname{PPAR} \gamma$, to the Gdnf promoter. This is the first description that the transcription of Gdnf is controlled by $\operatorname{PPAR} \alpha$. In the SNpc of PD patients, while dopaminergic neurons die, glial cells like astrocytes and microglia do not die. Moreover, astrocytes are the major glial cell in the CNS. Therefore, it would make sense to use existing astrocytes for the production of GDNF in vivo in the $\mathrm{SNpc}$ using gemfibrozil and other activators of $\operatorname{PPAR} \alpha$.

To delineate the protective role of astroglial GDNF in gemfibrozil-mediated protection of the nigrostriatum in vivo, at first we assessed GDNF protein levels in the nigra from both WT and PPAR $\alpha^{-1-}$ animals intoxicated with MPTP and treated with gemfibrozil. We found that WT mice, but not PPAR $\alpha^{-1-}$ mice, displayed a significant increase in GDNF expression in response to gemfibrozil treatment that was colocalized with GFAP-positive astrocytes. To be certain of the contributions of astrocytic GDNF in the protection of dopaminergic neurons, we used creflox recombination to create $G d n f^{\Delta a s t r o}$ mice. Importantly, gemfibrozil treatment led to significant rescue of nigral dopaminergic neurons, protection of striatal neurotransmitters, and significant reduction of motor deficits in MPTP-intoxicated Gdnf ${ }^{\text {cre }}$ mice, but not Gdnf ${ }^{\Delta a s t r o}$ mice. These results clearly demonstrate the necessity of astrocytic GDNF for the mitigation of nigrostriatal pathology observed in this animal model of $\mathrm{PD}$ in response to gemfibrozil. While the genetic deletion of GDNF is a very clean way to interrogate the necessity for GDNF, genetic omission often results in the ablation of many other downstream pathways. Therefore, pharmacological targeting of GDNF with an antibody may be another way to confirm the role of this nigral trophic factor in the neuroprotective effects of gemfibrozil.

Although gene therapy and stereotaxic injection of GDNF into the brain are definitely valid options, it seems that, from the therapeutic angle, the best option is to stimulate/induce the production of GDNF within the CNS of patients with PD. In this connection, it is wise to mention that a recent failure of a GDNF gene therapy trial in PD patients (Whone et al., 2019) probably occurred because of the fact that GDNF produced in the brain as a result of gene therapy or protein infusion does not reach the right target in the striatal microenvironment. On the other hand, when GDNF is generated in vivo in the brain by resident brain cells, our brain might be in a better position to send GDNF to the right target for its proper function.

In summary, here, we describe that gemfibrozil, a commonly prescribed FDA-approved lipid-lowering agent, stimulates the transcription of GDNF in astrocytes via PPAR $\alpha$ and reduces both the nigrostriatal pathology and motor deficits in the MPTP mouse model of PD via a PPAR $\alpha$-dependent astrocytic GDNF pathway. Given the epidemiological evidence linking lipid-lowering agents to a reduced prevalence of PD (Mutez et al., 2009), our findings suggest possible therapeutic implications of gemfibrozil for PD.

\section{References}

Berger JP, Akiyama TE, Meinke PT (2005) PPARs: therapeutic targets for metabolic disease. Trends Pharmacol Sci 26:244-251.

Burke RE (2006) GDNF as a candidate striatal target-derived neurotrophic factor for the development of substantia nigra dopamine neurons. J Neural Transm Suppl 70:41-45.
Chandra G, Roy A, Rangasamy SB, Pahan K (2017) Induction of adaptive immunity leads to nigrostriatal disease progression in MPTP mouse model of Parkinson's disease. J Immunol 198:4312-4326.

Chandra S, Pahan K (2019) Gemfibrozil, a lipid-lowering drug, lowers amyloid plaque pathology and enhances memory in a mouse model of Alzheimer's disease via peroxisome proliferator-activated receptor $\alpha$. J Alzheimers Dis Rep 3:149-168.

Corbett GT, Roy A, Pahan K (2012) Gemfibrozil, a lipid-lowering drug, upregulates IL-1 receptor antagonist in mouse cortical neurons: implications for neuronal self-defense. J Immunol 189:1002-1013.

Corbett GT, Gonzalez FJ, Pahan K (2015) Activation of peroxisome proliferator-activated receptor $\alpha$ stimulates ADAM10-mediated proteolysis of APP. Proc Natl Acad Sci U S A 112:8445-8450.

Dasgupta S, Roy A, Jana M, Hartley DM, Pahan K (2007) Gemfibrozil ameliorates relapsing-remitting experimental autoimmune encephalomyelitis independent of peroxisome proliferator-activated receptor-alpha. Mol Pharmacol 72:934-946.

di Michele F, Longone P, Romeo E, Lucchetti S, Brusa L, Pierantozzi M, Bassi A, Bernardi G, Stanzione P (2003) Decreased plasma and cerebrospinal fluid content of neuroactive steroids in Parkinson's disease. Neurol Sci 24:172-173.

Diederich NJ, Fénelon G, Stebbins G, Goetz CG (2009) Hallucinations in Parkinson disease. Nat Rev Neurol 5:331-342.

Dietz GP, Valbuena PC, Dietz B, Meuer K, Müeller P, Weishaupt JH, Bähr M (2006) Application of a blood-brain-barrier-penetrating form of GDNF in a mouse model for Parkinson's disease. Brain Res 1082:61-66.

Emamzadeh FN, Surguchov A (2018) Parkinson's disease: biomarkers, treatment, and risk factors. Front Neurosci 12:612.

Ghosh A, Pahan K (2012) Gemfibrozil, a lipid-lowering drug, induces suppressor of cytokine signaling 3 in glial cells: implications for neurodegenerative disorders. J Biol Chem 287:27189-27203.

Ghosh A, Roy A, Liu X, Kordower JH, Mufson EJ, Hartley DM, Ghosh S, Mosley RL, Gendelman HE, Pahan K (2007) Selective inhibition of NFkappaB activation prevents dopaminergic neuronal loss in a mouse model of Parkinson's disease. Proc Natl Acad Sci U S A 104:1875418759.

Ghosh A, Roy A, Matras J, Brahmachari S, Gendelman HE, Pahan K (2009) Simvastatin inhibits the activation of p21ras and prevents the loss of dopaminergic neurons in a mouse model of Parkinson's disease. J Neurosci 29:13543-13556.

Ghosh A, Corbett GT, Gonzalez FJ, Pahan K (2012) Gemfibrozil and fenofibrate, Food and Drug Administration-approved lipid-lowering drugs, up-regulate tripeptidyl-peptidase 1 in brain cells via peroxisome proliferator-activated receptor $\alpha$ : implications for late infantile Batten disease therapy. J Biol Chem 287:38922-38935.

Ghosh A, Jana M, Modi K, Gonzalez FJ, Sims KB, Berry-Kravis E, Pahan K (2015) Activation of peroxisome proliferator-activated receptor $\alpha$ induces lysosomal biogenesis in brain cells: implications for lysosomal storage disorders. J Biol Chem 290:10309-10324.

Gottschalk CG, Roy A, Jana M, Kundu M, Pahan K (2019) Activation of peroxisome proliferator-activated receptor- $\alpha$ increases the expression of nuclear receptor related 1 protein (Nurr1) in dopaminergic neurons. Mol Neurobiol 56:7872-7887.

Hindle JV (2010) Ageing, neurodegeneration and Parkinson's disease. Age Ageing 39:156-161.

Howells DW, Porritt MJ, Wong JY, Batchelor PE, Kalnins R, Hughes AJ, Donnan GA (2000) Reduced BDNF mRNA expression in the Parkinson's disease substantia nigra. Exp Neurol 166:127-135.

Jackson-Lewis V, Przedborski S (2007) Protocol for the MPTP mouse model of Parkinson's disease. Nat Protoc 2:141-151.

Jana M, Pahan K (2012) Gemfibrozil, a lipid lowering drug, inhibits the activation of primary human microglia via peroxisome proliferator-activated receptor $\beta$. Neurochem Res 37:1718-1729.

Jana M, Jana A, Liu X, Ghosh S, Pahan K (2007) Involvement of phosphatidylinositol 3-kinase-mediated up-regulation of I kappa B alpha in antiinflammatory effect of gemfibrozil in microglia. J Immunol 179:41424152.

Jana M, Mondal S, Gonzalez FJ, Pahan K (2012) Gemfibrozil, a lipid-lowering drug, increases myelin genes in human oligodendrocytes via peroxisome proliferator-activated receptor- $\beta$. J Biol Chem 287:34134-34148.

Kalia LV, Lang AE (2015) Parkinson's disease. Lancet 386:896-912. 
Khasnavis S, Pahan K (2014) Cinnamon treatment upregulates neuroprotective proteins Parkin and DJ-1 and protects dopaminergic neurons in a mouse model of Parkinson's disease. J Neuroimmune Pharmacol 9:569581.

Khasnavis S, Roy A, Ghosh S, Watson R, Pahan K (2014) Protection of dopaminergic neurons in a mouse model of Parkinson's disease by a physically-modified saline containing charge-stabilized nanobubbles. J Neuroimmune Pharmacol 9:218-232.

Kordower JH, Emborg ME, Bloch J, Ma SY, Chu Y, Leventhal L, McBride J, Chen EY, Palfi S, Roitberg BZ, Brown WD, Holden JE, Pyzalski R, Taylor MD, Carvey P, Ling Z, Trono D, Hantraye P, Déglon N, Aebischer P (2000) Neurodegeneration prevented by lentiviral vector delivery of GDNF in primate models of Parkinson's disease. Science 290:767-773.

Lovett-Racke AE, Hussain RZ, Northrop S, Choy J, Rocchini A, Matthes L, Chavis JA, Diab A, Drew PD, Racke MK (2004) Peroxisome proliferatoractivated receptor alpha agonists as therapy for autoimmune disease. $\mathrm{J}$ Immunol 172:5790-5798.

Mhyre TR, Boyd JT, Hamill RW, Maguire-Zeiss KA (2012) Parkinson's disease. Subcell Biochem 65:389-455.

Mondal S, Rangasamy SB, Roy A, Dasarathy S, Kordower JH, Pahan K (2019) Low-dose maraviroc, an antiretroviral drug, attenuates the infiltration of $\mathrm{T}$ cells into the central nervous system and protects the nigrostriatum in hemiparkinsonian monkeys. J Immunol. Advance online publication. Retrieved May 1, 2019. doi: 10.4049/jimmunol.1800587.

Mutez E, Duhamel A, Defebvre L, Bordet R, Destée A, Kreisler A (2009) Lipid-lowering drugs are associated with delayed onset and slower course of Parkinson's disease. Pharmacol Res 60:41-45.

Pahan K, Jana M, Liu X, Taylor BS, Wood C, Fischer SM (2002) Gemfibrozil, a lipid-lowering drug, inhibits the induction of nitric-oxide synthase in human astrocytes. J Biol Chem 277:45984-45991.

Patel D, Roy A, Kundu M, Jana M, Luan CH, Gonzalez FJ, Pahan K (2018) Aspirin binds to PPAR $\alpha$ to stimulate hippocampal plasticity and protect memory. Proc Natl Acad Sci U S A 115:E7408-E7417.
Prorok T, Jana M, Patel D, Pahan K (2019) Cinnamic acid protects the nigrostriatum in a mouse model of Parkinson's disease via peroxisome proliferator-activated receptor $\alpha$. Neurochem Res 44:751-762.

Roy A, Pahan K (2009) Gemfibrozil, stretching arms beyond lipid lowering. Immunopharmacol Immunotoxicol 31:339-351.

Roy A, Liu X, Pahan K (2007) Myelin basic protein-primed T cells induce neurotrophins in glial cells via alphavbeta3 [corrected] integrin. J Biol Chem 282:32222-32232.

Roy A, Jana M, Corbett GT, Ramaswamy S, Kordower JH, Gonzalez FJ, Pahan K (2013) Regulation of cyclic AMP response element binding and hippocampal plasticity-related genes by peroxisome proliferator-activated receptor $\alpha$. Cell Rep 4:724-737.

Smith WG, Wang J, Dang AQ, Reeves C, Bibbs D, Faas FH (2002) Gemfibrozil lowers plasma lipids and increases polyunsaturated fatty acid content and oxidative susceptibility of lipoproteins in hypertriglyceridemia. Clin Chim Acta 322:77-84.

Tieu K, Perier C, Caspersen C, Teismann P, Wu DC, Yan SD, Naini A, Vila M, Jackson-Lewis V, Ramasamy R, Przedborski S (2003) D-beta-hydroxybutyrate rescues mitochondrial respiration and mitigates features of Parkinson disease. J Clin Invest 112:892-901.

Whone A, Luz M, Boca M, Woolley M, Mooney L, Dharia S, Broadfoot J, Cronin D, Schroers C, Barua NU, Longpre L, Barclay CL, Boiko C, Johnson GA, Fibiger HC, Harrison R, Lewis O, Pritchard G, Howell M, Irving C, et al. (2019) Randomized trial of intermittent intraputamenal glial cell line-derived neurotrophic factor in Parkinson's disease. Brain 142:512-525.

Xu J, Storer PD, Chavis JA, Racke MK, Drew PD (2005) Agonists for the peroxisome proliferator-activated receptor-alpha and the retinoid $\mathrm{X}$ receptor inhibit inflammatory responses of microglia. J Neurosci Res 81:403-411.

Zhang X, Wang S, Hu L, Wang J, Liu Y, Shi P (2019) Gemfibrozil reduces lipid accumulation in SMMC-7721 cells via the involvement of PPAR $\alpha$ and SREBP1. Exp Ther Med 17:1282-1289. 